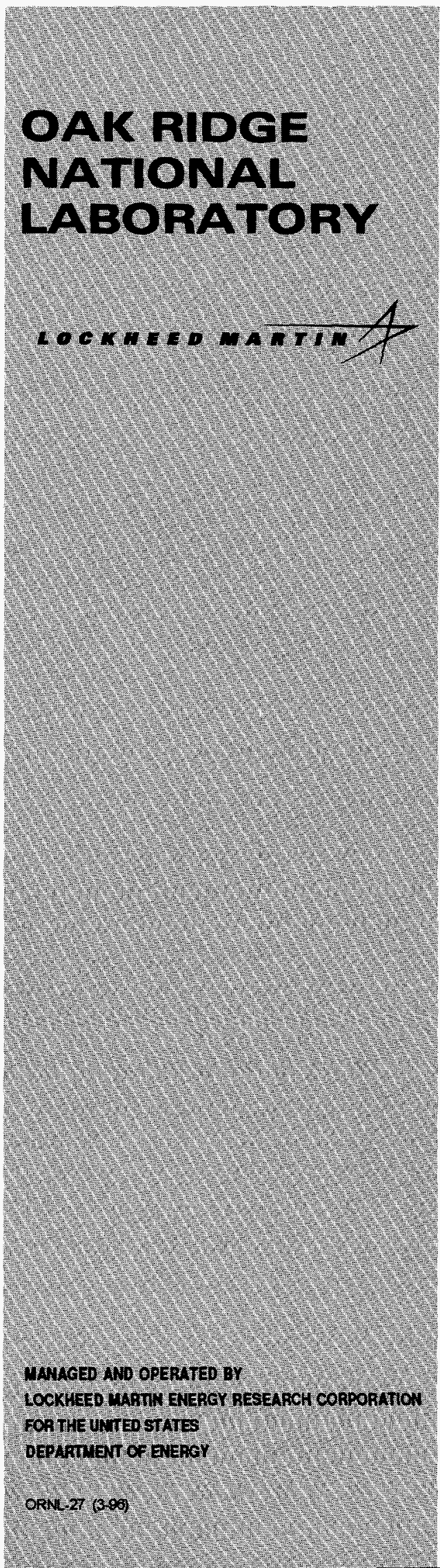

Lawrence J. Hill

\title{
Economic-Efficiency Considerations in Restructuring Electric Markets
}

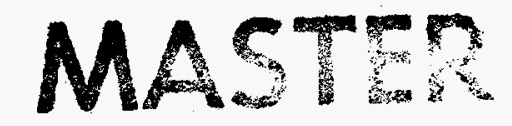

JA1 ? 91997

OSTI 
This report has been reproduced directly from the best available copy.

Avallable to DOE and DOE contractors from the Office of Scientific and Technical Information, P.O. Box 62, Oak Ridge, TN 37831; prices available from (423) 576-8401, FTS 626-8401.

Available to the public from the National Technical Information Service, U.S. Department of Commerce, 5285 Port Royal Rd., Springfield, VA 22161.

This report was prepared as an account of work sponsored by an agency of the United States Government. Neither the United States Government nor any agency thereof, nor any of their employees, makes any warranty, express or implied, or essumes any legal liability or responsibility for the accuracy, completeness, or usefulness of any information, apparatus, product, or process disclosed, or represents that its use would not infringe privately owned rights. Reference herein to any specific commercial product, process, or service by trade name, trademark, manufacturer, or otherwise, does not necessarily constitute or imply its endorsement, recommendation, or favoring by the United States Government or any agency thereof. The views and opinions of authors expressed herein do not necessarily state or reflect those of the United States Government or any agency thereof. 


\title{
Economic-Efficiency Considerations in Restructuring Electric Markets
}

\author{
Lawrence J. Hill \\ Energy Division
}

December 1996

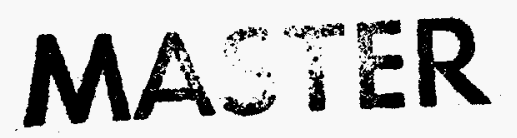

\section{Sponsored by the}

Office of Utility Technologies

Office of Energy Efficiency and Renewable Energy

U.S. Department of Energy

Prepared by the

OAK RIDGE NATIONAL LABORATORY

Oak Ridge, Tennessee 37831

Managed by

LOCKHEED MARTIN ENERGY RESEARCH CORP.

for the

U.S. DEPARTMENT OF ENERGY

under Contract No. DE-AC05-96OR22464 
DISCLAIMER

Portions of this document may be illegible in electronic image products. Images are produced from the best available original document. 


\section{Contents}

List of Figures and Tables

Acknowledgments vii

Summary ix

1. Introduction

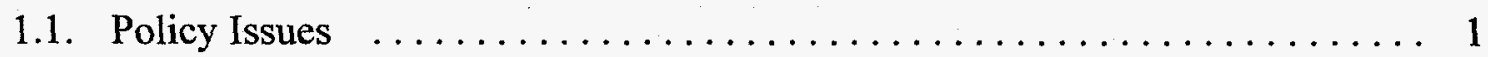

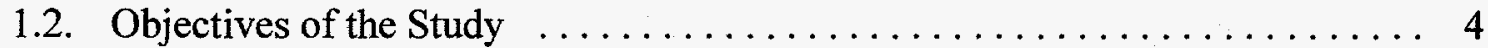

1.3. Sources of (In)efficiency in Existing and Restructured Markets ........ 4

1.4. Remainder of the Report $\ldots \ldots \ldots \ldots \ldots \ldots \ldots \ldots \ldots \ldots$

2. Efficiency in Existing Electric Markets $\ldots \ldots \ldots \ldots \ldots . \ldots 9$

2.1. Economic Regulation of Natural Monopolies $\ldots \ldots \ldots \ldots \ldots \ldots \ldots$. 9

2.2. Electric Utilities as Natural Monopolies: The Concepts $\ldots \ldots \ldots \ldots \ldots \ldots$

2.3. Electric Utilities as Natural Monopolies: The Evidence $\ldots \ldots \ldots \ldots \ldots .14$

2.3.1. Vertical Integration . . . . . . . . . . . . . . . . . . 15

2.3.2. Generation and Transmission (Bulk Power Systems) $\ldots \ldots \ldots \ldots 16$

2.3.3. Distribution Systems .......................... 22

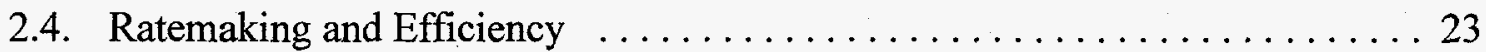

3. Efficiency in Restructured Electric Markets $\ldots \ldots \ldots \ldots \ldots \ldots$

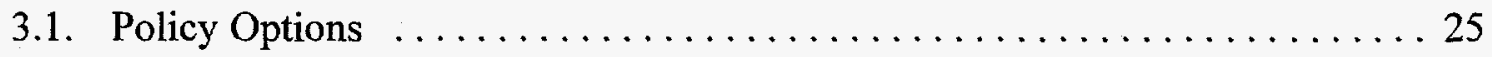

3.2. Restructured Electric Markets: A Prototype $\ldots \ldots \ldots \ldots \ldots \ldots \ldots \ldots 26$

3.2.1. Market Participants ............................. 28

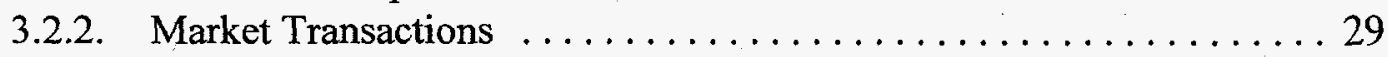

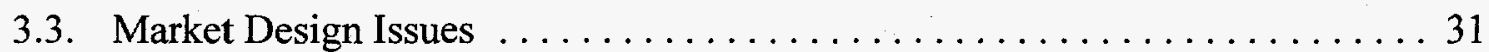

3.3.1. Functional Vs. Corporate Unbundling $\ldots \ldots \ldots \ldots \ldots \ldots \ldots \ldots \ldots$

3.3.2. Ratemaking and the ISO ...................... 33

3.3.3. Decentralized Relationship between the ISO and TLOs $\ldots \ldots \ldots 35$

3.3.4. Decisionmaking on Expansion of the Grid ............... 36

3.3.5. Consolidation of Control Areas ....................... 37

3.4. Loss of Vertical Economies and Other Costs $\ldots \ldots \ldots \ldots \ldots \ldots \ldots \ldots \ldots$

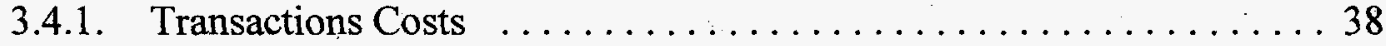

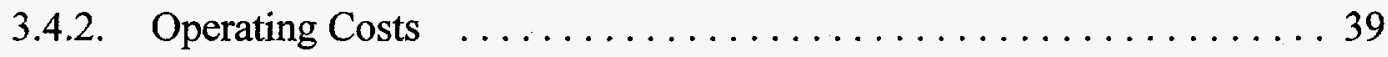




\section{Contents (Cont.)}

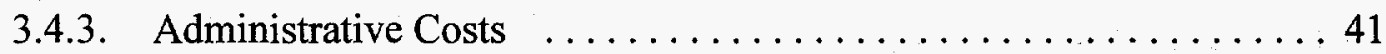

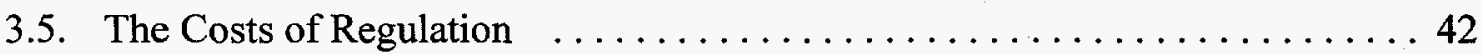

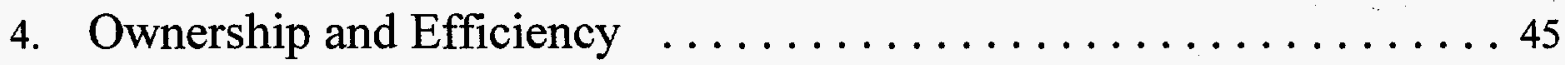

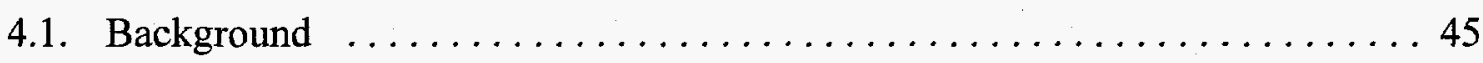

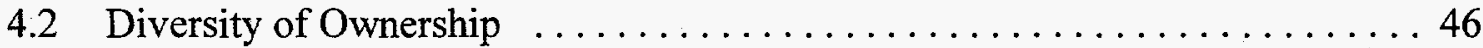

4.3. Relative Efficiency of Ownership Types $\ldots \ldots \ldots \ldots \ldots \ldots \ldots \ldots \ldots 48$

4.3.1. Differences among IOUs, POUs, and RECs $\ldots \ldots \ldots \ldots \ldots \ldots 48$

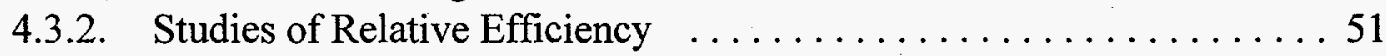

4.4. Ownership and Efficiency of Electric Markets $\ldots \ldots \ldots \ldots \ldots \ldots \ldots \ldots$

5. Conclusions ... .......................... 59

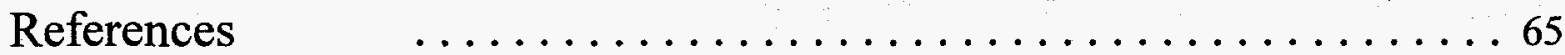




\section{List of Figures and Tables}

Figure

Description

Page

1

From Utility Functions to Market Participants in Electric

Markets

Potential Sources of Efficiencies and Inefficiencies, Existing $\ldots \ldots \ldots$

Electric Markets

Natural Monopoly Characteristics of the Electric Industry

Control Areas in the North American Power System

20

5

A Restructured Market Prototype $\ldots \ldots \ldots \ldots \ldots \ldots \ldots \ldots \ldots$

6

Transactions in a Restructured Market Prototype

30

7

Control Areas by Ownership in the U.S. Electric Industry

57

Table

Description

Page

1

Ten Largest and Smallest Control Areas in the United States,

Ranked by 1994 Peak Demand

U.S. Electric Generating Capacity, By Ownership Type, 1994

Summary of Studies Comparing the Resource Efficiency of

Ownership Types 



\section{Acknowledgments}

We benefitted greatly from many comments on a draft of this study. They include those of Les Baxter (Oak Ridge National Laboratory); Dave Boomsma (U.S. Department of Energy); Matthew Brown (National Conference of State Legislatures); Paul Carrier (U.S. Department of Energy); Joel Eisenberg (Oak Ridge National Laboratory); Joe Eto (Lawrence Berkeley Laboratory); Chris Garbacz (Mississippi Public Utilities Commission); Eric Hirst (Oak Ridge National Laboratory); Richard McMahon (Edison Electric Institute); David Penn (American Public Power Association); Artie Powell (Utah Public Service Commission); Rich Scheer (Energetics); and Steve Stoft (Lawrence Berkeley Laboratory). Any remaining errors, oversights, or misinterpretations are soley those of the author. 



\section{Summary}

In response to the Energy Policy Act of 1992 and the Federal Energy Regulatory Commission's subsequent rulemaking on transmission access, many states are exploring options to restructure their electric industries. Among the important considerations in their deliberations on restructuring, policymakers should consider (1) the reliability of the electric system; (2) income-distribution effects on ratepayers and utilities; (3) social consequences such as effects on energy conservation, renewable energy, and the environment; and (4) economic efficiency. We address economic-efficiency considerations in this study.

Economic efficiency is important because it is one of the primary reasons that policymakers should consider restructuring in the first place: improving the electric-industry's efficiency lowers costs and, hence, electric prices. In this study, we look at the sources of (in)efficiency in existing and proposed electric markets with the objective of guiding policymakers to design efficient electric markets.

Where feasible, introducing competition into otherwise inefficient markets has been the tool historically used by policymakers to increase economic efficiency. The advantages of a competitive market are well known: it leads to lower costs for the utility, lower prices for consumers, more product choices, better customer service, and often the need for less regulation by federal and state agencies. In the short run, firms who cannot produce at the market-clearing price are forced to leave the industry, ensuring that customers have the lowest price possible. In the long run, competition promotes innovation and lower costs.

The physical and institutional characteristics of the U.S. electric industry, however, could be impediments to attaining efficiently run, competitive markets. Because of these characteristics, there are multiple sources of efficiencies and inefficiencies in existing electric markets, and there will be multiple sources in restructured ones. The objective of policymakers should not be to trade one set of inefficiencies in existing electric markets for another set in restructured markets.

To avoid this possibility, policymakers must understand the source and extent of (in)efficiencies in both the existing market and any alternatives under consideration. Current policy debates focus largely on the importance of wholesale and retail competition in attaining economic efficiency at the expense of more subtle sources of (in)efficiencies. In this regard, the following questions are also appropriate when considering market alternatives:

${ }^{1}$ We emphasize resource efficiency; allocative efficiency is given less emphasis. Generally, a firm is more resource-efficient than another if it can produce goods at lower costs. A firm is allocatively efficient if the prices of its products approach marginal costs. We discuss efficiency-related concepts at greater length in Chapter 1. 
- Are there significant economies of vertical coordination between the generation and transmission stages of the market and, if so, are they sacrificed by eliminating price and entry regulation in the generating stage and de-integrating the generation and transmission stages?

Are there significant economies of vertical coordination between the transmission and distribution stages and, if so, are they sacrificed by de-integrating the transmission and distribution stages?

- Are there significant economies of scope in generation and, if so, are they lost by de-coupling the production of real power, reactive power, and other ancillary generating services?

- If there are no significant economies of scope in producing real and reactive power and other ancillary services, what is the most economical way to provide ancillary services? Markets? Contracts?

- Are there significant economies of scale in bulk power markets? Is the least-cost solution for the industry obtained by using the present system of 146 control areas in North America (138 in the United States)? More? Less?

Are there significant economies of scale in distributing electric power? What is the minimum efficient scale in distribution? Do economies of density and size preclude more than one distributor in a region?

- What about the relative efficiency of different ownership types in the industry? With renewed sentiment for the municipalization of local distribution systems, are municipally owned utilities more efficient than investor-owned ones? With increasing sentiment for the sale of federally owned utilities to the private sector, are investor-owned utilities more efficient than federally owned ones?

- Related, do subsidized input costs for publicly and cooperatively owned utilities impede efficient operation of existing electric markets? Restructured electric markets?

- What about alleged ratemaking-induced inefficiencies in existing electric markets such as the Averch-Johnson effect and X-inefficiency? Is restructuring necessary to correct these inefficiencies or is it sufficient simply to change ratemaking practices?

- Does the proposed market structure and ratemaking plan for the independent system operator and transmission-line owners in restructured electric markets provide proper incentives for these entities to minimize system costs? 
Unfortunately, answers to most of these questions do not exist. A striking characteristic of information on the electric industry is the imbalance between the conceptual and empirical. Although economic theory dealing with the industry is quite mature, there is little quantitative evidence on the cost structure of electric utilities to guide policymakers on restructuring decisions. And, in many cases where evidence exists, it is dated. This information shortfall makes sound comparisons between alternative market structures on an economic-efficiency basis very difficult. The shortfall makes sound prescriptions for efficient market structures just as difficult.

The existing evidence suggests that there are economies of vertical integration between the generation and transmission stages of a bulk power system. ${ }^{2}$ Therefore, those advocating the de-integration of the generation and transmission stages must show that the real cost savings from competition in generation exceed the foregone economies of vertical integration. Alternatively, they must show that the creation of an alternative market institution such as an independent system operator can recover these vertical economies.

There may also be significant economies of vertical integration between the transmission and distribution stages of an electric delivery system. Unfortunately, there are no studies quantifying these economies. Statistical studies of the industry typically combine the transmission and distribution stages of the network as one. Because restructuring proposals typically de-integrate transmission and distribution, the amount of these economies is an important input in determining the efficiency of restructuring proposals.

Electric generators produce more than one output. Besides real power, they produce reactive power, frequency control, and other ancillary services such as spinning and operating reserves. If there are economies of scope in producing real power and ancillary services, they may be sacrificed by creating a competitive wholesale power market. Unfortunately, there are no studies addressing generation scope economies.

Allowing the transmission stage to continue as a natural monopoly, controlled by an independent system operator, is one of the most important features of most restructuring proposals. Scale is an important consideration here. What is the most efficient size of a bulk power system? There are 138 bulk power systems (control areas) in the United States. Should an independent system operator be created for each one? Should they be consolidated? Unfortunately, there are no statistical studies of scale economies of bulk power systems to guide policymakers.

Most restructuring proposals assume that distribution is also a residual natural monopoly after deregulating the generation stage. But how large must a distribution system be to exploit function.

${ }^{2}$ Bulk power systems consist of generation and transmission assets and a dispatch (or control) 
scale economies? Can two distribution systems be created where one exists today? The existing evidence suggests that there are limited economies of size and density in distribution. Therefore, large distribution areas could be served by two or more distributors without loss of efficiency.

Little is known with certainty about the relative efficiency of ownership forms in the industry. First, research on relative efficiency has excluded federal utilities (the power marketing agencies and Tennessee Valley Authority). Second, the results of existing studies cannot guide policymakers on the efficiency effects of municipalizing local distribution facilities. The evidence on whether municipally owned utilities are more or less efficient than investor-owned ones is inconclusive.

The institutional features of restructured electric markets will be important determinants of their efficiency. In creating new electric markets, policymakers should pay special attention to five features: (1) ownership of vertical stages (functional vs. corporate unbundling); (2) the type of ratemaking imposed on the independent system operator and transmission-line owners (costof-service vs. performance-based vs. output- or revenue-based; (3) the structure of the relationship between transmission-line owners and the independent system operator (property rights considerations); (4) decisionmaking on expansion of the grid (independent system operator, transmission-line owners, or users of the grid); and (5) consolidation of control areas (many vs. few). The interrelationships of these institutional characteristics will affect the incentives of market participants and, therefore, the efficiency of a restructured market. 


\section{Introduction}

\subsection{Policy Issues}

The arguments to do something about the structure of electric markets are compelling to many. According to those arguments, federal policy toward the electric industry makes vertically integrated electric markets anachronistic. The prescription of the Energy Policy Act of 1992--implemented by the Federal Energy Regulatory Commission's (1996) recent rulemaking on transmission access--requires that transmission-line owners provide open access to all generators on a non-discriminatory basis. To abide by these federal mandates, state policymakers must replace the current mechanism by which generating plants are dispatched by transmission-line owners because these owners have an incentive to discriminate against independent generators that may want to enter wholesale markets.

Moreover, as the argument goes, the electric industry is inefficient. Economic regulation-and cost-of-service ratemaking--were imposed on the industry nearly a century ago when generating technologies were in their infancy. Technology has changed. Competition should replace regulation where appropriate to improve the efficiency of the industry. Replacing regulated markets with competitive ones has worked to varying degrees in other regulated industries such as transportation (railroads, trucking, and airlines), banking, and energy (oil and natural gas) in the past two decades. Therefore, it can work in the electric industry.

Ownership of utilities in the industry is a double-edged argument. On one hand, public ownership of distribution systems should be considered as a policy option to give "captive customers"--i.e., customers with fewer options than large industrial customers--monopsony power in restructured electric markets. As the argument goes, this municipalization will not affect economic efficiency because publicly owned utilities are at least as efficient as privately owned ones. On the other hand, the Tennessee Valley Authority and federal power marketing agencies should be privatized because, in part, they would be more efficient in the hands of private owners.

Finally, other countries such as Argentina, Australia, Bolivia, Chile, New Zealand, Norway, Spain, and the United Kingdom are restructuring their electric markets to improve efficiency. Many argue that U.S. electric markets should likewise be restructured to lower costs and, hence, electric prices.

In light of these arguments, policymakers at federal, state, and local levels continue to debate the advantages and disadvantages of restructuring their electric markets. With some degree of wholesale and retail competition existing in markets already and still more competition inevitable in the future, policymakers can take one of two routes: 
- Allow the industry's structure to evolve, ensuring open access to transmission lines for any potential entrant in the generating stage of the industry and letting competitive forces emerge over time. Modest policy changes such as substituting performance-based for cost-of-service ratemaking could also be considered.

- Restructure the industry more radically, allowing (1) competition in the generating stage of the industry and (2) retail customers direct access to electric suppliers of their choice.

Figure 1 depicts a more radical restructuring, moving the industry from vertically integrated functions (generation, dispatch, transmission, distribution, and customer service) shown on the left to an industry based on market participants shown on the right. As in other competitive markets, generators in the restructured electric market supply electric services directly to customers or through intermediaries such as brokers, marketers, existing distribution companies, and a futures market. Customers are free to choose their suppliers and types of electric services and can enter into contracts to hedge against risk. Because of the physical characteristics of an electric grid, other institutions (i.e., market-enhancers) should be created to ensure that independent generators are not denied access to the grid. The most widely discussed market-enhancer is an independent system operator, organizationally and financially independent of any other participant in the market, whose responsibility is to operate the bulk power system. A spot market for electricity that would serve as the foundation for other financial transactions is another new institution that would facilitate competition. ${ }^{1}$

In deciding whether to switch from an existing market structure to a restructured one shown in Figure 1, policymakers should consider four issues: (1) the reliability of the electric grid; (2) social consequences such as restructuring's effects on energy conservation and the environment; (3) income-distribution effects on ratepayers and utilities; and (4) economic efficiency. In this paper, we address economic-efficiency considerations. Economic efficiency is important because it is the very reason for considering restructuring in the first place: competition enhances economic efficiency, lowering electric supply costs and retail prices.

In general, economic efficiency can be broken into two parts: (1) allocative and (2) resource. Allocative efficiency refers to a firm's pricing of goods and services and its effect on resource allocation: the closer price is to marginal cost, the more efficient the allocation of resources in a given market. Resource efficiency refers to a firm's use of inputs: given a level of output, a firm is more resource-efficient than another if it can produce that output at lower cost. ${ }^{2}$

${ }^{1} \mathrm{~A}$ market structure of this type will be discussed at length in Chapter 3.

${ }^{2}$ Resource efficiency appears by different names in the literature, oftentimes tailored to the specific application or source of the efficiency. Crew and Kleindorfer (1986), for example, distinguish between X-efficiency, scale efficiency, and dynamic efficiency in discussing the resource efficiency of. 
Figure 1

From Utility Functions to Market Participants in Electric Markets

From

Utility

Functions

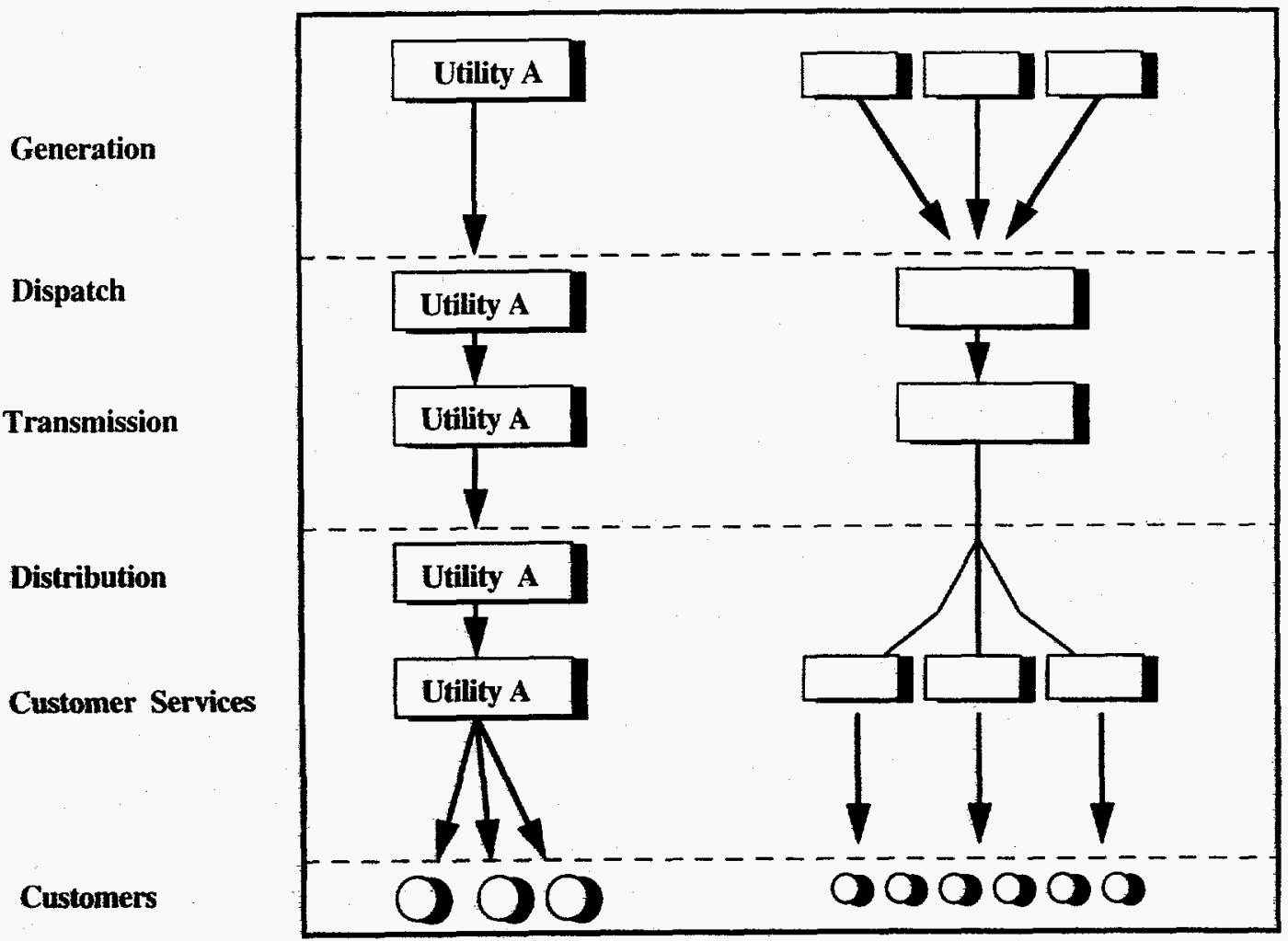

To

Market

Participants

Generators

Market-

Enhancers

Internediaries

Customers

electric utilities. In a more general discussion of resource inefficiency, Zieschang (1983) breaks out total cost inefficiency into technical and price components. Furthermore, price inefficiency can be relative or absolute. X-inefficiency, due to the contribution of Liebenstein (1966), is a type of resource inefficiency. The Averch-Johnson effect (Averch and Johnson, 1962) is also a type of resource inefficiency. We discuss these latter two types of inefficiencies in Chapter 2. 


\subsection{Objectives of the Study}

In considering restructuring, policymakers must understand the multiple sources of efficiencies and inefficiencies in both existing and restructured markets. The trade-off in policymaking is not simply between a regulated monopoly and a competitive market. The physical delivery system and decentralized ownership, regulation, and decisionmaking in the U.S. electric industry are too complicated for this simplistic thinking. Rather, the trade-off is between one set of (in)efficiencies in existing electric markets and potentially another set in restructured ones. Knowledge of the sources of (in)efficiency in existing markets can help policymakers devise more efficient restructured markets.

Our objective in this study is to identify sources of (in)efficiency in existing and restructured electric markets. For existing markets, we explore the historical economicefficiency considerations in regulating electric utilities as natural monopolies. For restructured markets, we develop a prototype and examine how economic efficiency can be affected by different design features of the market. We also consider the efficiency of public and private forms of ownership in both markets.

The objective of the study is not to estimate the cost-effectiveness of vertically integrated markets in comparison with restructured ones. A study of this type depends crucially on specific characteristics of local markets (e.g., degree of vertical integration, presence of non-investorowned utilities, generating mix). Rather, our objectives here are more modest: (1) to point out what efficiencies may be sacrificed in restructuring electric markets as depicted in Figure 1 (e.g., economies of vertical integration in existing markets); (2) to guide policymakers in designing new markets by identifying the cost structure of electric utilities (e.g., minimum efficient scale of bulk power and distribution systems; relative efficiency of public vs. private utilities); and (3) to guide policymakers in designing new markets by discussing institutional issues that may impinge on economic efficiency in restructured markets (e.g., form of ratemaking; decisionmaking on transmission investments).

To accomplish these objectives in a systematic way, we divide the study into efficiency considerations in (1) existing electric markets; (2) restructured electric markets; and (3) utility ownership. We provide an overview of these considerations in the next section of this chapter and a "road map" for the remainder of the report in Section 4.

\subsection{Sources of (In)efficiency in Existing and Restructured Markets}

Figure 2 illustrates the potential sources of efficiency and inefficiency in existing electric markets. To facilitate the presentation, the figure contains only two utilities. This simplification 
Figure 2

Potential Sources of Efficiencies and Inefficiencies

Existing Electric Markets

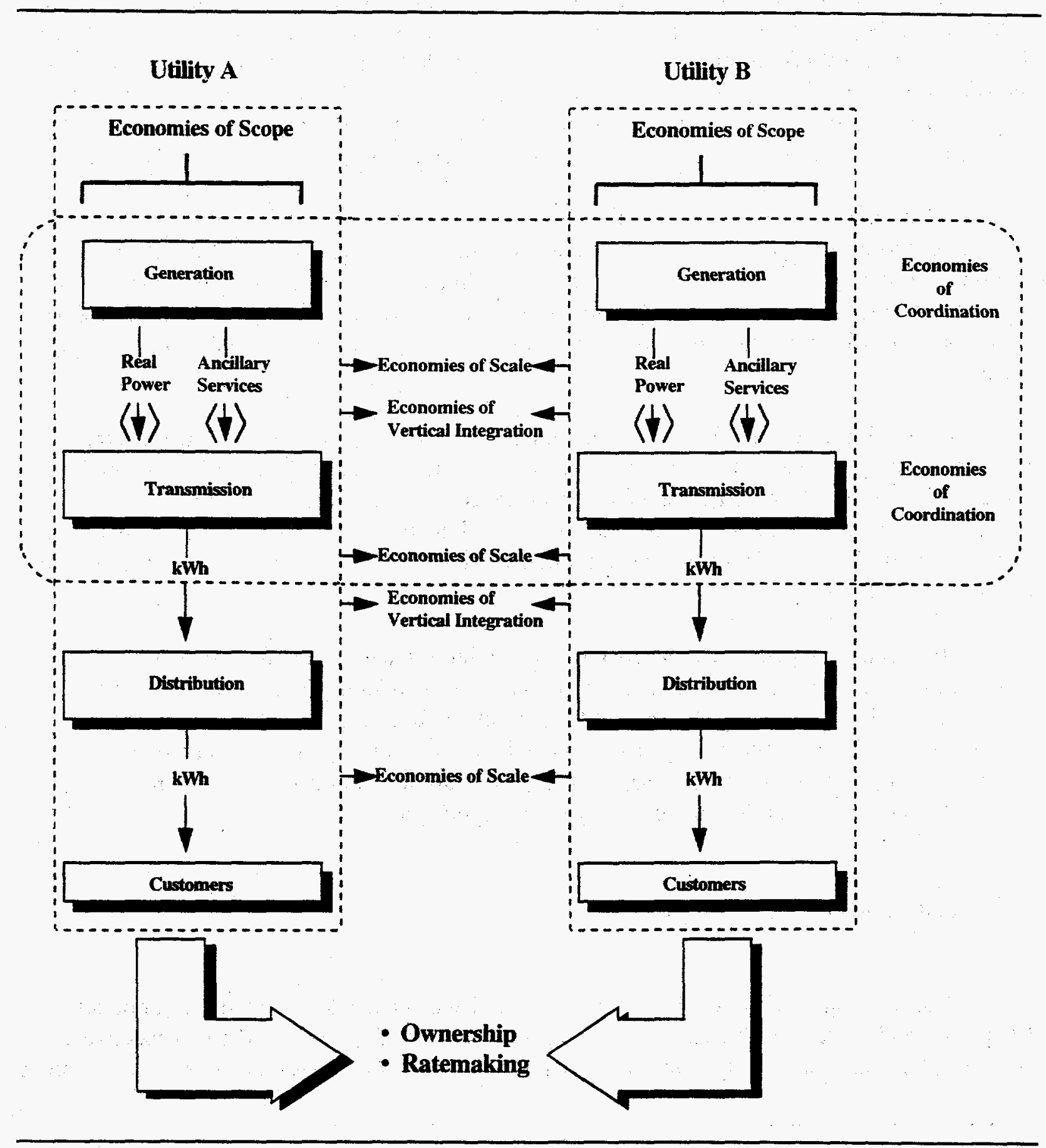


does not detract from our major points.

Utilities A and B are vertically integrated monopolies that generate, transmit, and distribute electric energy. They have historically been regulated as natural monopolies because, individually, they can produce and deliver electric energy at less cost than two or more utilities. The sources of these efficiencies are economies of (1) scale (costs decline as output increases in the various stages); (2) scope (cost savings from producing two or more products in a given stage), and (3) vertical integration (cost savings from one firm producing intermediate products in two successive stages of a vertical structure, rather than two or more firms). ${ }^{3}$

Economies of coordination in Figure 2 refer to two or more utilities coordinating their generation and/or transmission operations to reduce costs. Figure 2 shows Utilities A and B coordinating the generation and transmission stages. In existing electric markets, coordination occurs in (1) spot markets in which electric utilities buy and sell non-firm power and (2) formal power pools in which utilities coordinate generation and transmission to reduce electric supply costs.

Ownership and ratemaking have efficiency implications in all stages of the industry. Economic theory suggests that publicly owned firms are less efficient than privately owned ones. For electric utilities, the empirical evidence does not confirm or refute this hypothesis conclusively. Pure cost-of-service ratemaking in which there is no regulatory lag is a theorized source of inefficiency for investor-owned utilities because it does not provide utilities incentives to use inputs efficiently.

Restructured electric markets also have potential efficiencies and inefficiencies. The promise of deregulating price and entry restrictions in the generating stage is lower electric supply costs. However, design features of the market could lead to higher costs, even to the extent of exceeding the efficiency gains associated with introducing competition in the generating stage. Costs could increase because of institutional arrangements in the new market, the loss of vertical economies, and more regulatory oversight.

\subsection{Remainder of the Report}

The remainder of the report explores these efficiency considerations in greater detail. Chapters 2 and 3 address efficiency in existing and restructured electric markets, respectively. Both chapters deal exclusively with vertically integrated, investor-owned utilities. These utilities

${ }^{3}$ Economies of scope can be generalized to include economies of vertical integration. We distinguish between the two in this study because of their importance when discussing individual stages of the industry. 
currently dominate the industry. Chapter 4 extends the discussion of efficiency to include rural electric cooperatives and publicly owned utilities (those owned principally by municipalities, but also by counties, states, and the federal government).

Chapter 2 first addresses the natural monopoly characteristics of vertically integrated electric utilities, including economies of scale, scope, and vertical integration. We look for empirical evidence of natural monopoly in the industry in total and at each of its individual stages. Is the industry a natural monopoly? If not, are some of the individual stages natural monopolies? What is known about the minimum efficient scale of each of the stages?

Economies of vertical integration between stages? The chapter then considers ratemaking as a source of inefficiency in existing markets.

Chapter 3 addresses efficiency considerations of a prototypical restructured electric market, discussed at length in the second section of the chapter. The efficiency of restructured markets can potentially be affected by market-design features, the loss of vertical economies, and increases in regulation costs. Market-design features include: (1) functional vs. corporate unbundling; (2) the relationship between the independent system operator and transmission-line owners; (3) ratemaking by the ISO; (4) decisionmaking on transmission expansion; and (5) the degree of aggregation across control areas when creating the ISO.

Chapter 4 addresses ownership as a potential source of (in)efficiency. We emphasize two issues. The first is whether publicly owned utilities are more or less resource-efficient than privately owned ones. The second is the relationship between ownership, subsidies, and resource efficiency in competitive generating markets.

Chapter 5 discusses limitations in our current understanding of the cost structure of electric utilities and the efficiency effects of design features in restructured markets; how these limitations can affect sound decisionmaking on restructuring; and what can be done to advance our understanding of the structural and institutional characteristics of more efficient electric markets. 


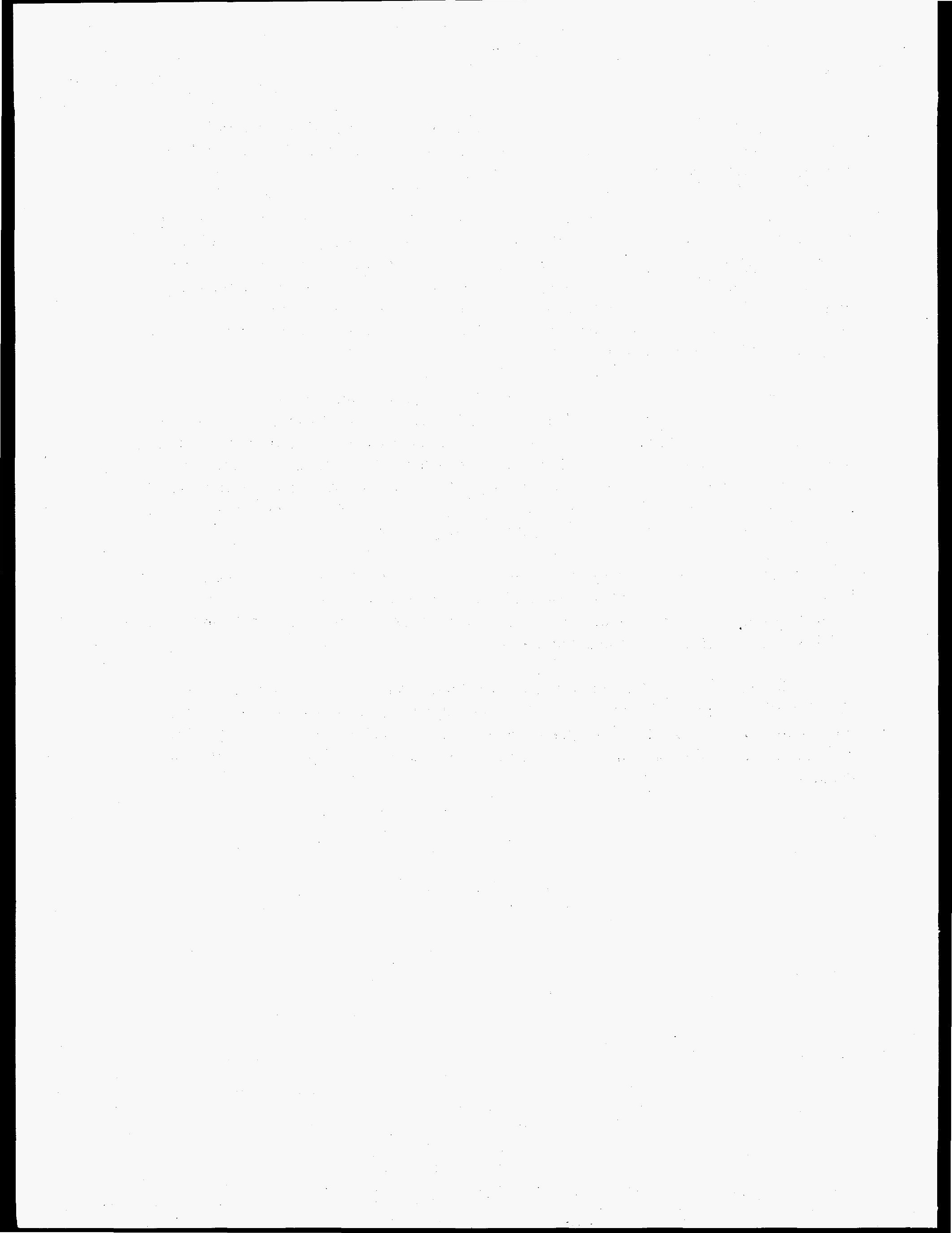




\section{Efficiency in Existing Electric Markets}

\subsection{Economic Regulation of Natural Monopolies}

Economic theory suggests that competitive markets serve economic welfare better than non-competitive or regulated markets. In competitive markets, the prices at which goods and services are sold tend toward their marginal costs. Because the additional benefits and costs of producing more goods and services tend to be equal, society's resources are allocated efficiently.

If the government does not intervene in an economy, however, resources may not be allocated to all markets in this way because of "market failures." A market failure is a condition that, over time, prevents the price of a commodity from approaching its marginal cost of production. On economic efficiency grounds, the existence of a market failure justifies government intervention in the economy. ${ }^{1}$ These failures fall into four categories:

- imperfect competition (the cost structure of some industries precludes price from moving toward marginal cost without government intervention);

- externalities (the unintended side effects of producing and consuming goods);

- imperfect information (asymmetry of information between producers and consumers);

- public goods (goods that would not be produced without government intervention).

For imperfect competition, the technical and cost characteristics of some industries are such that, without government intervention, competition would be limited, firms would earn excess profits, and economic efficiency would be sacrificed in the process. If left alone in an industry of this type, a firm with the financial wherewithal to obtain the initial capital would be able to monopolize it. The firm could increase prices above marginal costs, prevent entry into the industry, earn excess profits, and produce too little of the good based on society's demand for the product. A firm in an industry such as this is called a natural monopoly if it can produce all of the industry's output at lower cost than two or more firms. For a vertically integrated industry,

${ }^{1}$ This is the "public interest" justification for government intervention in markets. There are competing theories that explain why governments intervene. One of the more prominent alternatives, the "Chicago theory of regulation," is not as inclined to justify the existence of regulation on the basis of regulators' good intentions with respect to the public interest. 
the output of each vertical stage is relevant. ${ }^{2}$

To correct potential abuses and avoid inefficient behavior, natural monopolies are subject to economic regulation. That is, the prices that they are allowed to charge consumers are approved by regulatory commissions created to regulate monopolies of this type. Entry into the industry is also restricted so that the monopoly can fully exploit all of its inherent cost advantages. The goal of economic regulation is to mimic to the greatest extent possible the functioning of a competitive market. ${ }^{3}$

Historically, utilities in the electric industry have been regulated as natural monopolies. In return for an exclusive franchise to sell electricity in a defined area, electric utilities have been allowed to operate as monopolies in these areas. In return, they are subject to economic regulation: prices are regulated and entry into the industry is restricted.

Current policymaking that promotes restructuring of electric markets disowns the historical view of electric utilities as natural monopolies, vertically integrated from production through transmission and distribution. Many policymakers would like to substitute competition for regulation--at least in the generation stage of the industry-- keeping the transmission and distribution stages as regulated monopolies.

From an economic-efficiency standpoint, the challenge for those advocating restructuring in this way is to show that the technical and cost characteristics of the industry that led to regulating electric utilities as natural monopolies in the first place no longer exist. For those advocating deregulation of the generation stage of the industry, the challenge is to show that it is no longer a natural monopoly. A further challenge is to justify continuing regulation of the remaining stages of the industry. Is the transmission stage a natural monopoly? Is the distribution stage also?

\subsection{Electric Utilities as Natural Monopolies: The Concepts}

Figure 3 shows the stages of a vertically integrated electric utility, the outputs at each stage, and the possible sources of economic efficiencies both within and between stages. The

\footnotetext{
${ }^{2}$ Technically, this condition refers to subadditivity of the firm's cost function. For further details, see Baumol, Panzar, and Willig (1982). A summary is provided below.

${ }^{3}$ Not all industries subject to economic regulation have historically been or are currently. natural monopolies. Some industries are regulated for other reasons such as political, legislative, or legal ones. Competition in the trucking industry, for example, was historically limited by legislative policy. Today, some agricultural industries are regulated for political reasons.
} 
Figure 3

Natural Monopoly Characteristics of the Electric Industry
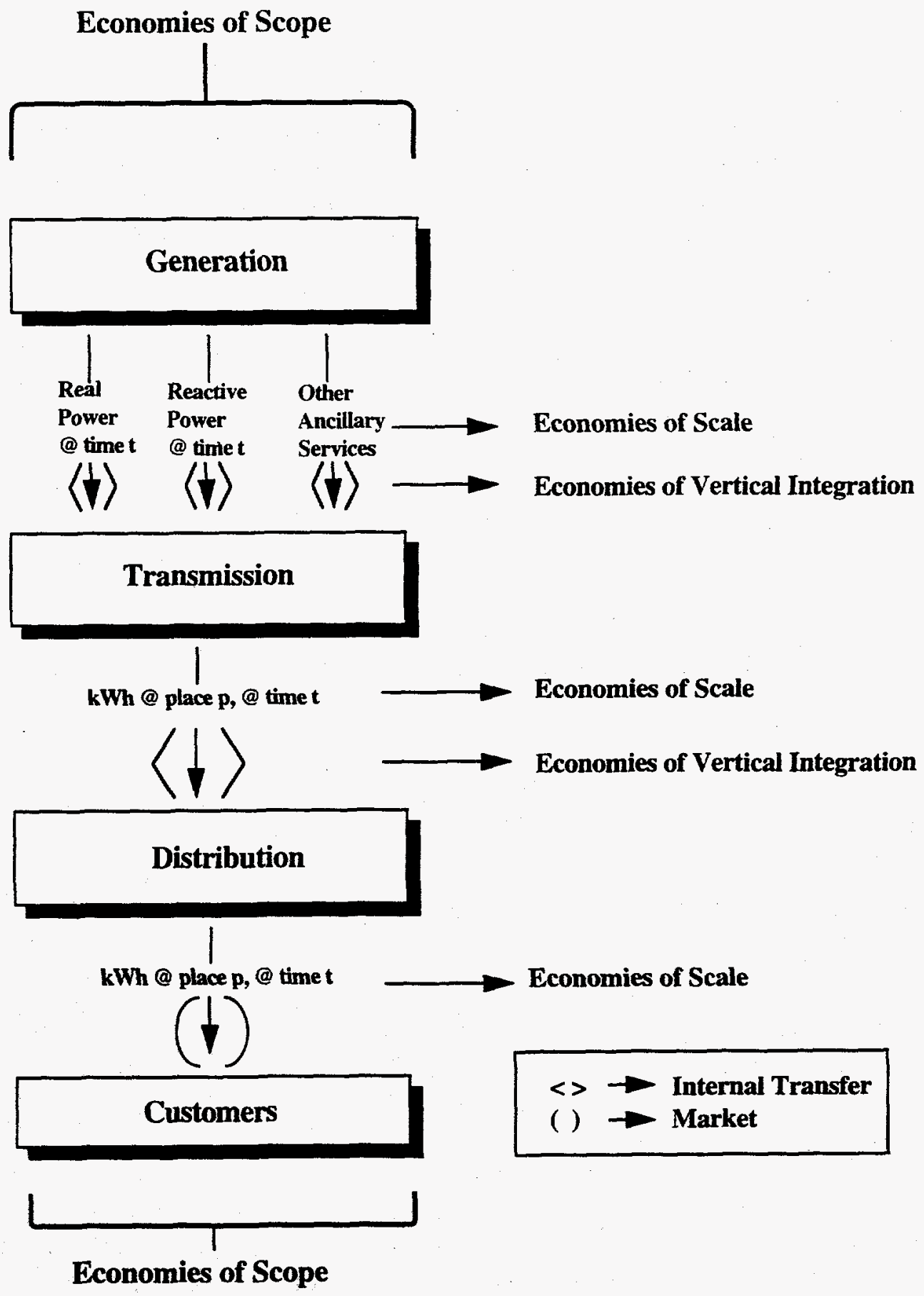
utility generates real power, reactive power, and other ancillary services. ${ }^{4}$ The outputs of the generating stage are transmitted (usually higher voltage) and distributed (usually lower voltage) to electric customers. The diamonds $(\diamond)$ in Figure 3 indicate that $\mathrm{kWh}$ are transferred internally by the electric utility without the use of markets; the circle [O] indicates that the $\mathrm{kWh}$ are sold in a market. ${ }^{5}$

The electric utility in Figure 3 produces multiple products at each horizontal stage of the industry. In the generation stage, the utility produces real power, reactive power, and other ancillary services. Each of these outputs can be further differentiated by time. Because of timevarying load on a delivery system, a $\mathrm{kWh}$ produced at peak hours, for example, typically costs more than a $\mathrm{kWh}$ produced during off-peak hours. At the transmission and distribution stages, the utility's output is electric energy (measured in $\mathrm{kWh}$ ) which also can be differentiated by time.

Figure 3 shows three potential sources of economies or efficiencies in an electric system: economies of (1) scope, (2) scale, and (3) vertical integration. Each of these economies figures prominently in determining whether the electric utility as a whole--or any of its individual vertical stages--is a natural monopoly.

Because it produces multiple products at each of its three stages, economies of scope are an important potential source of efficiencies for a vertically integrated utility. Scope economies refer to the joint production of two or more products. Economies of scope exist if it is cheaper for one firm to produce two or more products than it is for two or more firms to produce these products. For example, it may be cheaper to procure an input to produce real power and reactive power jointly than to procure that same input separately for producing real and reactive power. In this example, the utility's scope of operations at the generation stage leads to real cost savings.

A second potential source of economies shown in Figure 3 is related to scale. If costs decline as the production of any of the outputs at any of the stages increases over a relevant range, the production of that output exhibits scale economies. The cost behavior for production of each of the outputs at a given stage does not necessarily have to be the same. For example, the production of real power may exhibit scale economies while the production of reactive power

${ }^{4}$ Generators and, to a lesser extent, transmission networks provide ancillary services to maintain the reliability of an electric delivery system. These services include reactive power, frequency control, and other reserves such as spinning and supplemental operating. For detailed discussions of ancillary services and their costs, see Federal Energy Regulatory Commission (1996), Hirst and Kirby (1996), and Kirby and Hirst (1996).

${ }^{5}$ The electric utility characterized in Figure 3 is totally integrated from generation through transmission to distribution. In reality, only electric utilities in isolated areas and not interconnected with other utility systems (such as those on islands) are totally integrated. Most utilities purchase and sell electricity on wholesale spot markets. They are in reality vertically integrated in part. We abstract from that possibility here for purposes of clarity without detracting from our major points. 
may not.

Vertical economies are a third potential source of real cost savings in a vertically integrated electric system. ${ }^{6}$ That is, it may be less costly for a single firm to produce real and reactive power and other ancillary sevices and transmit and distribute that power to customers than it is for separate firms to produce and sell the output at each of the three stages. Vertical economies arise from many sources, but technical interdependence is especially important in the electric industry. The electric system is interconnected from generators through transmitters and distributors to ultimate customers. Independent operation of the stages may sacrifice the economies associated with interdependence.

In planning a power delivery system, each stage of the industry is a substitute for each other to varying degrees. For example, generating plants and transmission lines are substitutes for one another. More investment in strategically placed transmission facilities obviates the need for some generating capacity. A similar argument can be made for transmission and distribution investments. To the extent that these trade-offs in planning are made more efficiently by a single firm operating in the three stages than by two or more separate firms, there are economies of vertical integration.

Related, access to information on each stage is important when planning expansion of the system. The design and siting of a generating plant, for example, requires detailed information on the transmission and distribution systems and any planned changes to those systems. To the extent that this information flows more freely and accurately within a vertically integrated firm than in two or more separate ones, resulting in better investment decisions and cost savings, there are economies of vertical integration.

In operating the system, the physical interdependence among stages requires substantial coordination to provide power to loads on the system. The ancillary services needed to deliver this power require a high degree of coordination between the three stages of the delivery system. Any change on the distribution and transmission stages, for example, affects the generating stage. If de-integrating the system leads to higher costs in delivering real power from generators to customers, economies of vertical integration are sacrificed.

The synergy between economies of scale, scope, and vertical integration are important in determining whether the utility as a whole in Figure 3 is a natural monopoly or whether any of the individual stages exhibit natural monopoly characteristics. The existence of natural monopoly in the industry can be determined from the top down--the utility as a whole--or from the bottom up, beginning from individual stages and working to the whole.

${ }^{6}$ Vertical economies can also be viewed as scope economies across vertical stages rather than across a horizontal stage. We distinguish between the two here for clarity. 
Viewing it as a whole, the utility in Figure 3 is a natural monopoly--and should be granted an exclusive territorial franchise--if its cost function is subadditive. A cost function is subadditive if it is cheaper for one firm to produce the industry's output than two or more firms.

Viewing the firm from the bottom up at each stage of production, a sufficient condition for a natural monopoly in the production of one product is the existence of scale economies over the relevant range of output. For example, assume that real power is the only product of a firm in the generating stage of the industry. If the production of real power exhibits economies of scale over a range of output that includes market demand, the firm is a natural monopoly. Policymakers are then justified in granting a franchise to the monopoly firm to produce all of the market's requirments.

In the real-world case of a firm producing multiple outputs (such as real and reactive power and other ancillary services) in the generating stage of the industry, economies of scope must also be considered when evaluating the natural monopoly characteristics of the generating stage. In this case, the joint production of these products results in a natural monopoly if the subadditivity conditions are satisfied. If one firm can produce real and reactive power and other ancillary services cheaper than two or more firms, that firm is a natural monopoly.

Economies of vertical integration complicate the analysis of natural monopoly characteristics. Even if a vertical stage of the industry shown in Figure 3 does not exhibit natural monopoly characteristics when evaluated individually, it still could be a natural monopoly when considered in tandem with another stage if there are sufficient economies of vertical integration between the two stages. For example, even if the generating stage is not a natural monopoly when evaluated alone, it could still be considered a natural monopoly in tandem with the transmission stage if (1) the transmission stage is a natural monopoly and (2) there are sufficient economies of vertical integration between the two stages.

With these conceptual underpinnings of natural monopoly as background, we turn to the empirical literature to see what is known about the cost structure of electric utilities and whether or not they exhibit natural monopoly characteristics and at what stages.

\subsection{Electric Utilities as Natural Monopolies: The Evidence}

The statistical evidence on the natural monopoly characteristics of electric utilities is not as rich as its conceptual development. In fact, a striking conclusion is how little is actually known about the cost structure of the electric industry. This shortcoming is not peripheral, but rather relates to quantification of fundamental sources of efficiencies and inefficiencies in existing markets. 
Gilsdorf (1995) conducted the only study examining subadditivity of the cost structure of electric utilities. Looking at the vertically integrated structure, he found no evidence of natural monopoly in the industry. To our knowledge, there have been no studies of subadditivity in individual stages of the industry. The following three sections explore what is known about the cost structure of the industry: (1) economies of vertical coordination, (2) generation and transmission scale economies (the bulk power system), and (3) distribution scale economies.

\subsubsection{Vertical Integration}

The close vertical links between generation and transmission and transmission and distribution are themselves impediments to estimating the quantitative signficance of those links. Because the relationships among the three stages are blurred in the operation of an electric grid, it is very difficult to obtain accurate data on the extent of the relationships. Data from the Federal Energy Regulatory Commission's (FERC's) Form 1 is the source of information used by analysts to quantify the extent of vertical links in the industry. Form 1 requires electric utilities to separate generation, transmission, distribution, and other expenses into separate accounts. This accounting allocation does not necessarily reflect the three economic functions. For example, utilities must allocate fixed costs that apply to two or more stages to individual accounting categories.

With this caveat about data sources in mind, the weight of the evidence suggests that there are significant economies of vertical integration between the generation and transmissiondistribution stages. To our knowledge, there are no studies estimating the significance of vertical economies between the transmission and distribution stages of the industry. Analysts typically combine the transmission and distribution stages into one "distribution" stage.

Kaserman and Mayo (1991) report significant economies between the generation and transmission-distribution ("distribution") stages. They used a quadratic cost function for a sample of 74 electric-only utilities in 1981 (50 utilities operating in generation and distribution, 10 in generation only, and 14 in distribution only) to obtain their results.

The coefficient on the cross-product term $G^{*} D$ (the product of generation and distribution expenses) in their estimating equation is the key variable in Kaserman and Mayo's analysis. The coefficient indicates whether or not a utility that both generates and distributes electricity has lower costs than other utilities engaged in just one stage of the industry.

Kaserman and Mayo conclude that vertically integrated utilities at the mean of the sample have 12 percent lower costs than utilities not vertically integrated. Based on this evidence, the authors provide the following policy prescription:

... the evidence presented does place a heavy burden on proponents of 
deregulation schemes that are premised upon forced vertical divestiture in this industry (Kaserman and Mayo, 1991, p. 500).

In an earlier study, Henderson (1985) came to a similar conclusion using a different technique than Kaserman and Mayo. He tested the hypothesis that generation is separable from "generalized distribution," which, like Kaserman and Mayo, includes both the transmission and distribution stages of the industry. Using data for 160 investor-owned electric utilities in 1970, Henderson rejected the hypothesis that generation and distribution are functionally separable.

More recently, Thompson et al. (1996) estimated a restricted profit function for electric utilities, treating the amount of generation as an endogenous variable. The authors used a sample of 83 investor-owned electric utilities for the years 1977 and 1982 and 85 utilities for the years 1987 and 1992. However, because of problems with data in the earlier years, they only reported results for 1992. Using the generation to sales ratio as their basis, the authors conclude that vertical economies are significant:

... the optimal firm would generate about the same fraction of its final sales ( 77 percent) as the average 1992 firm (79 percent), but roughly at a 15 percent smaller scale of operation (Thompson et al., 1996, p. 32).

Similar to other analysts, Kwoka (1996) estimated the degree of vertical economies between generation and distribution, combining the transmission and distribution stages together as "distribution." Using a quadratic cost function similar to Kaserman and Mayo, Kwoka also found significant economies of vertical coordination. The sample he used was considerably larger than that used in the other studies: 543 electric utilities (147 investor-owned, 396 publicly owned) in 1989. Kwoka concludes:

For the average output combination (of utilities in the sample) ... these penalties (cost penalties from de-integration) are much higher--in excess of 38 percent, or equivalently, a cost savings of 27 percent from integration.

A recent study by Gilsdorf (1994) is the only one that even suggests vertical economies are not significant. Using a multiproduct translog cost function for 72 investor-owned utilities in 1985, Gilsdorf finds no cost complementarities between stages of the industry and, therefore, no significant vertical economies.

\subsubsection{Generation and Transmission (Bulk Power Systems)}

Existing statistical studies do not address the natural monopoly characteristics of the generation and transmission stages of the industry. They instead focus on scale economies in generation and transmission. As discussed above, scale economies are one aspect of the natural 
monopoly issue. Horizontal scope economies and vertical economies between stages are also important considerations in determining whether individual stages are natural monopolies.

Economies of scope, for example, may be important in the generating stage of the industry. Power plants produce real power and ancillary services such as reactive power, frequency control, and spinning and supplemental operating reserves. There may be economies in jointly producing real power and one or more of these ancillary services. These economies could be an important consideration in evaluating electric restructuring proposals that deintegrate the generation and transmission stages of the industry, requiring an independent system operator to procure ancillary services independently from generators either through contracts or in competitive markets.

Considering only scale economies, existing studies of the generating stage fragment the industry in two ways that could bias estimation of the extent of scale economies. First, they are typically fragmented by technology type, capturing only one of several different generating technologies. Because steam power historically dominated electric generation, most early studies address the cost of conventional steam-power production, ignoring other technologies. Nerlove (1963), Petersen (1975), and Christensen and Greene (1976) are prominent examples. More recent studies address other generating technologies. For example, Krautman and Solow (1988), Kamerschen and Thompson (1993), and Thompson and Wolf (1993) estimate scale economies for nuclear-steam technologies.

Second, statistical studies of scale economies in the generating stage universally focus on the costs of generating power to the exclusion of the costs of transmitting and distributing it. Failure to account for synergies between stages of the industry can lead to biased results (see discussion of vertical integration above). Cowing and Smith (1978) reviewed the early statistical work on scale economies in electricity generation. More recent studies include those by Krautman and Solow (1988), Kamerschen and Thompson (1993), and Thompson and Wolf (1993). Also, studies of the transmission stage focus exclusively on the costs of transmission to the exclusion of generation and distribution costs. Meyer (1975) and Huettner and Landon (1978) are examples of these types of studies.

Related to the second bias and as important, failure to conduct studies at the proper level of analysis can also bias results on scale economies in generating electricity. Early studies of scale economies in generation were conducted at the plant level (e.g., Johnston, 1952; Lomax, 1952). Later studies were conducted at the firm level. The study by Christensen and Greene (1976) is representative of the rationale for this level of analysis:

The regulated entity in the U.S. electric power industry is the firm. Thus, assessment ... requires information on economies of scale for firms--as opposed to plants or individual generating units.

Studies at the firm level generally show that scale economies are exhausted at fairly low 
levels of output. Using a translog cost function to estimate the cost structure for steam production of 114 investor-owned utilities in 1970, Christensen and Greene (1976) concluded that scale economies for electric utilities were exhausted at 3.8 gigawatts $(\mathrm{GW})$.

Estimating the production cost structure at the firm level in 1971, Huettner and Landon (1978) concluded that economies were exhausted at $1.6 \mathrm{GW}$. They used an ad hoc quadratic cost function to estimate the generating cost function for 74 utilities that sold power to residential, commercial, and industrial customers and used fossil-steam generation for at least 80 percent of their generation and provided at least 80 percent of their own power requirements (substantially vertically integrated).

Also working at the firm level and using a translog cost function to estimate the cost function for 40 investor-owned utilities that use both fossil-steam and nuclear generating technologies in 1985, Kamerschen and Thompson's (1993) conclusions on the cost structure of fossil-steam generating technologies are generally consistent with those of Huettner and Landon. The minimum efficient scale for electric generation is less than the $3.8 \mathrm{GW}$ reported by Christensen and Greene.

In evaluating the results of these studies at the firm level, however, one must consider the fuel and technology fragmentation issues raised above. If an electric utility owns one plant (with corresponding generation and transmission assets and a control function)--not interconnected with other plants--the proper level of analysis for determining scale economies is the utility level. Similarly, if the utility owns one transmission line, scale economies are significant for this line.

However, power systems contain more than one plant and transmission networks do not consist of point-to-point service exclusively. Transmission lines are typically configured in a grid, connecting generating plants and load centers. Because plants are interconnected in utilities and utilities are interconnected in bulk power systems, the minimum efficient scale estimated for individual utilities becomes less and less meaningful. A more appropriate level of analysis for estimating scale economies is the bulk power system.

To see this, consider a power delivery system, consisting of a bulk power system and one or more distribution systems. A bulk power system consists of (1) generating plants, (2) transmission lines linking the plants together into a network, and (3) a control center. The control center's primary responsibilities are to dispatch power plants, commit plants for operation and maintenance, and trade with adjacent control areas. Substations and transformers are located

${ }^{7}$ The cost of transmitting electricity from point to point is proportional to distance and the inverse of the square of a line's voltage. Therefore, increasing the voltage of a transmission line (its capacity), results in significant cost savings. Baldick and Kahn (1993) discuss the technical features of transmission lines that make it difficult to quantify precisely the cost structure of individual lines. 
near the generating plants and on transmission and distribution systems to change voltages as power moves through the system.

For reliability reasons, bulk power systems are organized as "control areas" by the North American Electric Reliability Council (NERC). According to NERC (1995), a control area is a ". . . system which regulates its generation in order to maintain its interchange schedule with other systems and contributes its frequency bias obligation to the interconnection."

Figure 4 shows the 146 control areas in the North American interconnected grid. U.S. utilities control 138 of them. Canada controls seven and Mexico one. The operator of each control area regulates the production and transmission of power in a specified geographical area. The operator also coordinates transactions with other control areas. Connections with other control areas are represented by the lines in the figure.

Control areas must meet the relibaility requirements of NERC. Presently, control areas consist of "tight" power pools (e.g., the Pennsylvania-Jersey-Maryland Pool, New York Power Pool, New England Power Exchange); holding companies (e.g., Southern Company Services, Entergy Electric System); individual utilities (private or publicly owned); or multiple utilities with one functioning as the control-area operator.

Given more than $800 \mathrm{GW}$ of dispatchable generating capacity in the United States, the average control area is approximately six GW. However, control areas deviate markedly from this average. Table 1 provides the peak demand of the ten largest and ten smallest U.S. control areas. The table indicates substantial variation in their size. The ten largest control areas account for 41.5 percent of U.S. peak demand; the ten smallest account for 0.2 percent. $^{8}$ Six of the seven largest control areas are either power pools or holding companies; the Tennessee Valley Authority is the exception. Eight of the ten smallest control areas are municipal utilities. ${ }^{9}$

If there are significant scale economies in the operation of a bulk power system, many of the smaller bulk power systems shown in Figure 4 are inefficient. If there are significant diseconomies of scale in bulk power operations beyond a certain level of output, many of the larger bulk power systems may also be inefficient.

The minimum efficient scale of bulk power systems and the possibility of diseconomies are important public-policy issues at the moment because some restructuring proposals call for the consolidation of control areas. In the California restructuring legislation, for example, the control areas of Pacific Gas and Electric, San Diego Gas and Electric, and Southern California

${ }^{8}$ Calculated from NERC (1995).

${ }^{9}$ Many utilities that own generating plants and transmission lines are not individual control areas; their generating plants are dispatched by other control areas. 
Edison will be consolidated and run by an independent system operator. The three publicly owned control areas in California must also agree to be part of the consolidated control area if they want to recoup transition costs from ratepayers.

Figure 4

Control Areas in the North American Power System

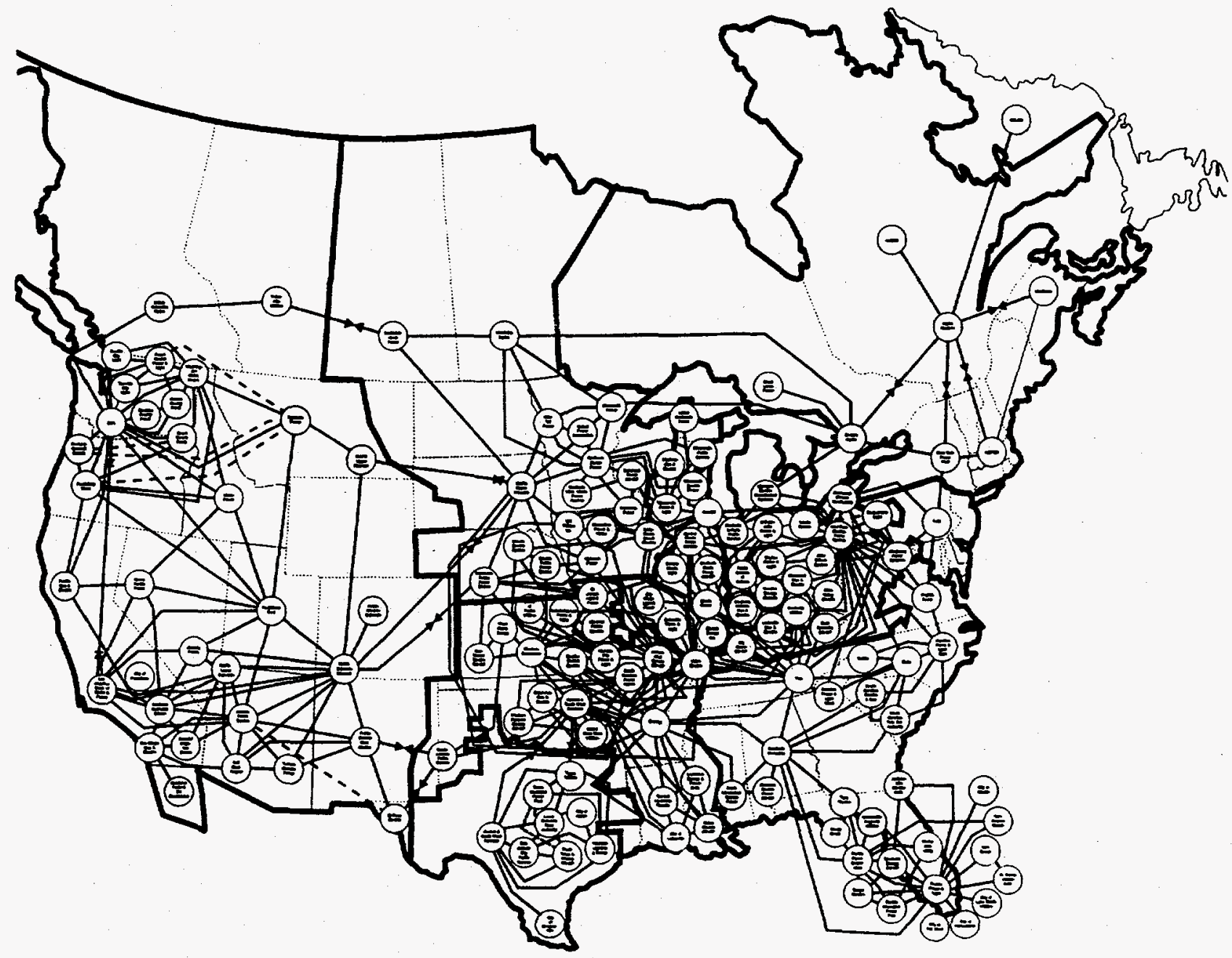

Source: North American Electric Reliability Council (1995). 
Table 1

Ten Largest and Smallest Control Areas in the United States

Ranked by 1994 Peak Demand

\begin{tabular}{|c|c|c|c|}
\hline Rank $^{\mathrm{a}}$ & Name & Organization & $\begin{array}{l}\text { Peak (MW) } \\
\text { Demand }\end{array}$ \\
\hline 1 & PJM Pool & Power Pool & 46,450 \\
\hline 2 & Southern Company Services & Holding Company & 32,600 \\
\hline 3 & New York Power Pool & Power Pool & 26,880 \\
\hline 4 & Tennessee Valley Authority & Federal Utility & 26,880 \\
\hline 5 & New England Power Exchange & Power Pool & 20,400 \\
\hline 6 & Entergy Electric System & Holding Company & 19,736 \\
\hline 7 & American Electric Power & Holding Company & 19,719 \\
\hline 8 & Pacific Gas \& Electric & Private Utility & 19,609 \\
\hline 9 & Texas Utilities & Private Utility & 18,968 \\
\hline 10 & Commonwealth Edison & Private Utility & 18,600 \\
\hline$\bullet$ & $\bullet$ & • & $\bullet$ \\
\hline • & • & - & • \\
\hline$\bullet$ & $\bullet$ & - & $\bullet$ \\
\hline 128 & Brownsville & Municipal Utility & 166 \\
\hline 129 & Reedy Creek & Municipal Utility & 145 \\
\hline 130 & Muscatine Power and Water & Municipal Utility & 142 \\
\hline 131 & Upper Peninsula Power Company & Private Utility & 140 \\
\hline 132 & Yadkin & Private Utility & 118 \\
\hline 133 & Key West & Municipal Utility & 108 \\
\hline 134 & New Smyrna Beach & Municipal Utility & 82 \\
\hline 135 & Lake Worth & Municipal Utility & 69 \\
\hline 136 & Homestead & Municipal Utility & 48 \\
\hline 137 & Starke & Municipal Utility & 13 \\
\hline
\end{tabular}

aDoes not include one Mexican and seven Canadian control areas. Hydro-Quebec $(30,890 \mathrm{MW})$ and Ontario-Hydro $(24,141 \mathrm{MW})$ would place third and sixth in a ranking of North American control areas.

No data were provided for the St. Cloud control area. Thus, the ranking is based on 137 control areas, rather than 138 . 
Other parts of the country are exploring consolidation of control areas. For example, seven electric utilities in the Northwest (Idaho Power, Montana Power, PacifiCorp, Portland General Electric, Puget Sound Power and Light, Sierra Pacific, and Washington Water Power) intend to form IndeGo, an independent system operator, to operate as a single control area by mid 1997. The Electric Reliability Council of Texas, which includes nine privately and publicly owned control areas in Texas, will also become an independent system operator by mid 1997.

Are these consolidations economically efficient? Unfortunately, there is no statistical evidence to answer this question.

Given this background, estimating scale economies for generating plants at the unit, plant, or utility level seems inappropriate unless an individual utility is also a control area. Control areas are the decisionmaking levels for bulk power systems. The control-area operator influences the supply costs of bulk power, given system conditions. The conditions include output of the control area, its size and configuration, the type of generating units, the use of those units, and the amount of trade conducted with other control areas.

\subsubsection{Distribution Systems}

As with bulk power systems, statistical studies of distribution systems focus on scale economies at the expense of scope and vertical economies between distribution and the bulk power system. Differentiating between transmission and distribution facilities is oftentimes difficult. Is a high-voltage line serving an end-use customer a transmission or distribution line? FERC is struggling with this issue at the present time. ${ }^{10}$ Indeed, in many cases in an integrated network, transmission and distribution are substitutes for one another. A strategically placed transmission line will obviate the need for distribution facilities. A strategically sized transmission line will accomplish the same thing.

The empirical literature stresses the relationships between costs and three features of distribution systems. Costs can increase because (1) existing customers consume more (economies of output density); (2) new customers come into an existing service area (economies of customer density); or (3) the service area increases in size (economies of size).

Although sketchy, the evidence suggests that economies of output density exist, but not economies of size or customer density. From a simple regression of average costs on average consumption and number of customers, Weiss (1975) concluded that distribution economies arise because of load densities, rather than size. Roberts (1986) confirms both of Weiss' conclusions and goes one step further. He disaggregated density economies into those

\footnotetext{
${ }^{10}$ Federal Energy Regulatory Commission (1995 and 1996).
} 
attributable to output per customer and those attributable to number of customers. He found no significant economies for customers, but significant economies for output. Thompson, Hovde, and Irwin (1996) corroborate Roberts' latter conclusion. Neuberg (1977) confirms the conclusion on size. Neuberg also found a traditional U-shaped cost curve for distribution, suggesting that, after some point, diseconomies of scale exist. Therefore, some distribution systems may be too large on an economic efficiency basis.

\subsection{Ratemaking and (In)efficiency}

Cost-of-service ratemaking (COSR) has been the predominant model since state commissions began regulating electric utility rates in 1907 . The principles of ratemaking under COSR are well known. First, a utility's allowed revenues are set equal to the total costs of running the utility: operation and maintenance expenses, depreciation, taxes, and a return on invested capital. Second, total revenues are allocated to customer classes to determine average rates. Allocative and resource inefficiencies are in-bred in this procedure.

Prices based on average costs are not allocatively efficient. Prices based on marginal costs are efficient because the incremental cost of producing the last unit of output is equal to the incremental benefit to consumers. The only ways in which average prices can equal marginal prices are (1) if average cost is constant over the relevant range of output or (2) the utility is operating on the minimum point of its average cost curve. In practice, electric utilities produce different outputs at different times of the day, week, and year--e.g., peak, shoulder, and off-peak hours. Marginal costs vary during these periods.

Resource inefficiencies stem from two sources. First, Averch and Johnson (1962) showed that a regulated firm subject to a binding rate-of-return constraint of the type used in COSR will tend to substitute capital for other inputs. The binding constraint means that the allowed rate of return on capital is greater than the market rate of capital and less than the profitmaximizing amount. If the condition holds, a regulated firm uses resources inefficiently and will not produce a given level of output as cheaply as a firm not subject to the same constraint.

Second, the source of another type of inefficiency under COSR is the ability of a regulated firm to pass costs on to ratepayers on a dollar-for-dollar basis. This feature of COSR does not provide regulated firms the incentives to minimize costs. For lack of a better term, Liebenstein (1966) called this "X-inefficiency." A firm subject to price and entry regulation will produce a given level of output at a higher cost than a firm not subject to this type of regulation.

Like the A-J effect, the existence of X-inefficiency is an empirical question. However, both are intuitively appealing. Requiring a firm to earn a rate of return less than the amount leading to profit maximization suggests that the firm would substitute capital for other inputs. 
And, insulating a firm from competitive pressures suggests that the firm may not be as cost conscious as if it were facing competition in a market. 


\section{Efficiency in Restructured Electric Markets}

\subsection{Policy Options}

Conventional wisdom suggests that, because of technological characteristics, price and entry regulation in the generating stage of the electric industry may no longer be justified. Thus, allowing vertically integrated firms to generate all of the capacity and energy needs in a geographical area may not be the most efficient market structure in the electric industry. Also, Chapter 2 showed that institutional factors may be a source of inefficiency in existing electric markets. Cost-of-service ratemaking (COSR), for example, is theoretically a source of inefficiency, providing incentives for utilities to use inputs inefficiently.

One possible way to eliminate the inefficiencies in existing electric markets is to change the rate-making approach from COSR to one based on performance. Performance-based ratemaking (PBR) such as price caps breaks the link between electric prices and costs, providing utilities with incentives to lower costs. The incentives to lower costs depend on specific features of the price-cap plan, including (1) the existence of profit sharing, (2) the amount of time between rate cases, and (3) the level of the caps (Hill, 1995; Comnes, Stoft, Greene, and Hill, 1995).

Another way to eliminate the alleged inefficiencies is to use the threat of entry as an incentive for electric utilities to lower costs. Baumol, Panzar, and Willig (1982) show that a monopolist threatened with potential entry will use resources efficiently and not earn monopoly profits in the long run. Cost-cutting by electric utilities in the past five years suggests that the threat of entry in the generating business may have already induced electric utilities to be more efficient.

Still a third way to eliminate the inefficiencies in vertically integrated markets is to restructure those markets, introducing competition where appropriate and changing institutions in residual portions of the industry to provide incentives for market participants to behave efficiently. Section 2 of this chapter outlines the features of one such restructured electric market. The restructured market is a composite of existing state-level restructuring proposals.

In the restructured market, competition replaces price and entry regulation in the generating stage of the industry. The three stages of the industry are vertically de-integrated, requiring arms-length transactions between generators and transmitters, and transmitters and distributors. A new institution, the independent system operator (ISO), is created to facilitate competition.

The benefits of introducing competition in the generating stage of the industry are well 
known. In the short run, entry of firms competing with existing utilities in the generating business will tend to move the supply price of electricity to its marginal cost. In the long run, competition tends to spur innovation, increasing the likelihood that the cost of producing electricity will be the lowest possible, given existing technology.

Other effects of restructured markets on economic efficiency are less well known, and are the subject of this chapter. Indeed, it is conceivable that increases in costs associated with new institutional arrangements in the industry required by electricity's unique characteristics could offset the efficiency gains from introducing competition in generating markets. ${ }^{1}$ The discussion in Sections 3 through 5 of this chapter addresses these less well known effects of restructuring: (1) inefficient design of market institutions; (2) loss of vertical economies and other cost increases; and (3) higher costs of regulation.

\subsection{Restructured Electric Markets: A Prototype}

The poolco and bilateral-contracts models are the two most widely discussed options to replace the existing structure of the electric industry. The poolco model contains a wholesale spot market for electricity that serves as the foundation for making transactions in the market. An auction in which electric generators bid their supply amounts at incremental points in time (e.g., half-hourly, hourly) is the basis of the market. The bilateral-contracts model is more decentralized. States allow retail customers direct access to power suppliers. Contracting for electric supply by generators and wholesale and retail customers is the basis of the market. Creation of a poolco, however, does not eliminate the possibility of bilateral transactions. In this study, we adopt a hybrid model that incorporates features of both the poolco and bilateral models.

Creation of an ISO is probably the most effective way to ensure competition in this hybrid market. An ISO is an independent corporate entity that performs the control function in a bulk power system. ${ }^{2}$. It controls the transmission grid on behalf of existing transmission-line owners (TLOs). Depending on how the market is organized, the ISO or another corporate entity could operate the bid-based spot market. In our prototype, the ISO operates the spot market.

Figure 5 shows the restructured electric market prototype. The spot market, run by the

${ }^{1}$ This statement refers to the long run. In the short run, electric prices could increase after deregulating generation if the transition costs from a regulated to a deregulated market are large and amortized over a sufficiently short period of time. Most of these transition costs are the assets and liabilities of electric utilities incurred before deregulation that are uneconomic in a restructured market.

${ }^{2} \mathrm{~A}$ bulk power system consists of generation and transmission assets and a control function. 
ISO, is not shown in the figure. Bilateral contracts in which customers contract with generators to supply electricity are part of the market and shown on the left of the figure. A futures market for electricity, shown on the right hand side of Figure 5, also exists.

Figure 5

\section{A Restructured Market Prototype}

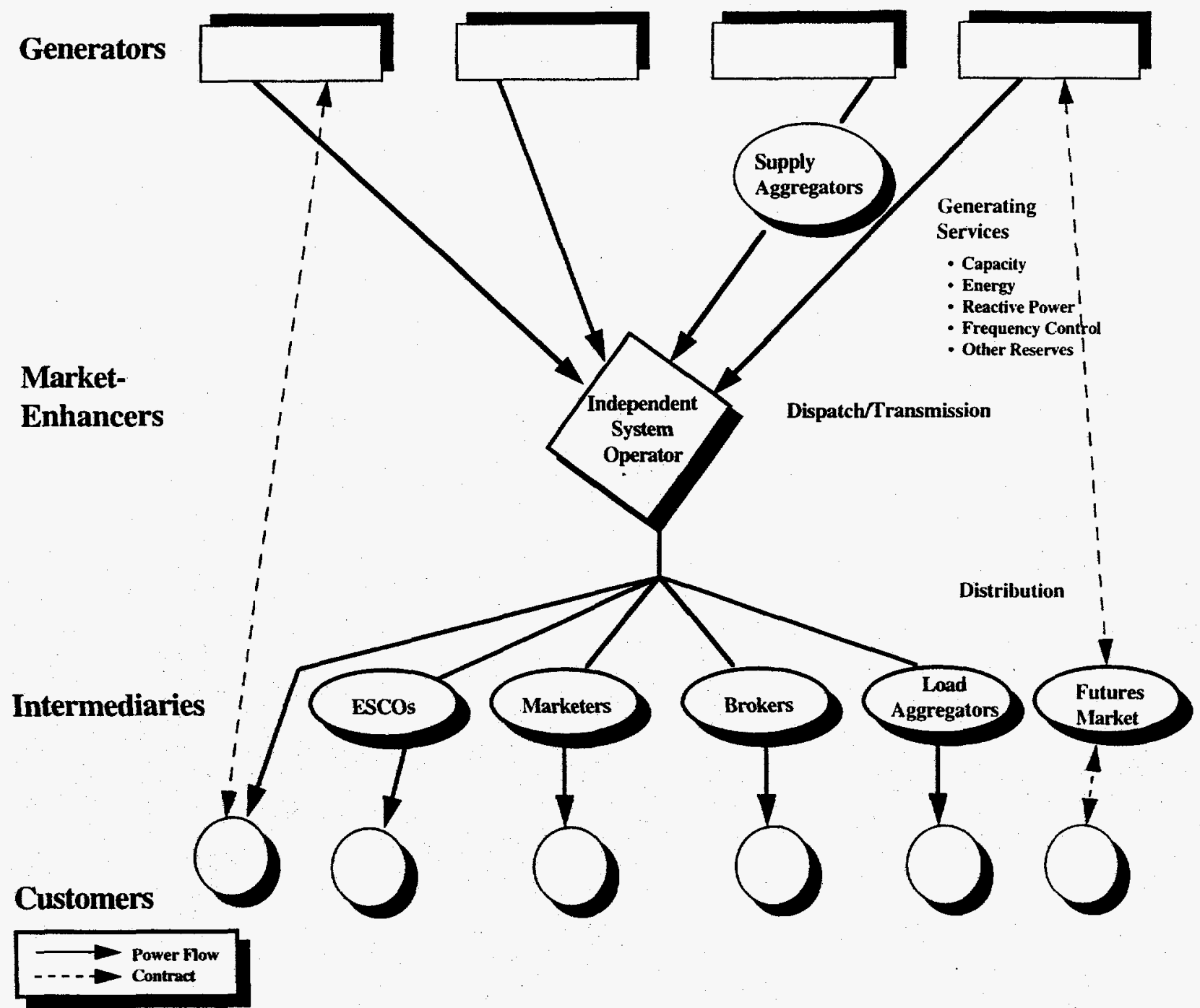




\subsubsection{Market Participants}

The generators shown in Figure 5 provide capacity, energy, and certain ancillary services. They can be (1) affiliated with previously integrated utilities (functional unbundling); (2) the divested (and now independent) companies of previously integrated utilities (corporate unbundling); or (3) unaffiliated with investor-owned utilities: municipals, cooperatives, exempt wholesale generators, cogenerators, and qualifying facilities. Generators can bid their output into the spot market and/or enter into bilateral contracts with customers or market intermediaries. The discussion below shows that incentives for generators differ under corporate and functional unbundling.

Ancillary Services will be unbundled, procured, and provided by the ISO or, if they so choose, provided by electric customers themselves. The services include reactive power, frequency control, and other operating reserves. The ISO will procure these services either by contract or through a bidding system from generators.

A supply aggregator is a financial intermediary that aggregates the output of two or more generating plants for sale to wholesale or ultimate customers. It identifies loads that can be served by two or more plants. The customer(s) then enter into a bilateral contract for the output of these plants.

Transmission-line owners could be independent companies divested from previously integrated utilities (corporate unbundling) or subsidiaries of existing vertically integrated utilities (functional unbundling). In either case, they do not control operation of--or access to--the grid. The business relationship between the ISO and TLOs is an important one. Incentives for the ISO vary, depending on whether there is centralized or decentralized decisionmaking in the transmission stage (discussed below). Also, as with generators, incentives for TLOs vary, depending on the type of vertical unbundling (functional or corporate).

Distribution companies could be independent companies divested from previously integrated utilities (corporate unbundling), subsidiaries of vertically integrated utilities, or previously distribution-only utilities. As with generators and TLOs, incentives vary with these ownership arrangements. Distributors receive revenues from two sources: (1) from the nondiscriminatory (common-carrier) use of their distribution lines to provide electricity to retail customers and (2) from the sale of electricity purchased from the spot market or under bilateral contracts from generators. Distributors may also provide energy services to customers (such as running energy conservation programs). In any case, distributors face competition from the following entities in the retail market:

- Energy service companies are market intermediaries that provide energy conservation services, information on energy efficiency, and financing services to retail customers. 
- Load aggregators are market intermediaries that combine two or more customers and pool their buying power either from the spot market or directly from generators under bilateral contracts. Load aggregators are especially important for small-volume customers whose buying power in the market would not be as great in the absence of aggregating.

- Brokers are market intermediaries that bring electric buyers and sellers together. A broker is a transaction-maker that does not actually purchase and resell electric services.

- Marketers, similar to brokers, are intermediaries that match buyers and sellers. Unlike brokers, they actually purchase generating services from suppliers and resell it to wholesale or retail customers.

\subsubsection{Market Transactions}

A nodal pricing system exists in the market prototype. The spot price at each node in the grid at any point in time depends on demand, supply, transmission losses, and grid congestion. The optimal spot price is the minimum system cost of dispatching one more $\mathrm{kWh}$ of electricity. ${ }^{3}$

Various types of financial instruments allow buyers and sellers to spread the risk of participating in the market. Bilateral contracts between generators and wholesale and retail customers are an integral part of the market. Generators can contract for fuel supplies at fixed prices. Wholesale and retail customers can purchase from the spot market and enter into a contract for differences between the spot market price and a negotiated price. Figure 5 shows that a futures market allows market participants to hedge on the price of electricity for 12- to 18month periods. None of these financial instruments are subject to economic regulation by the Federal Energy Regulatory Commission (FERC) or state commissions.

The ISO could possibly administer a system of transmission congestion contracts (TCCs) in which users of the transmission system are ensured financial payments from the ISO when the system is congested (to be discussed below). FERC would regulate TCCs.

Figure 6 shows the financial transactions to move electric generating services from generators to wholesale and retail customers in the restructured market. The solid arrows indicate regulated transactions; the broken arrows indicate unregulated ones. Generators can sell power to the ISO on the spot market or directly to customers under bilateral contracts. Each of

${ }^{3}$ For those with a technical background, the spot price at each node is its shadow price. 
Figure 6

Transactions in a Restructured Market Prototype

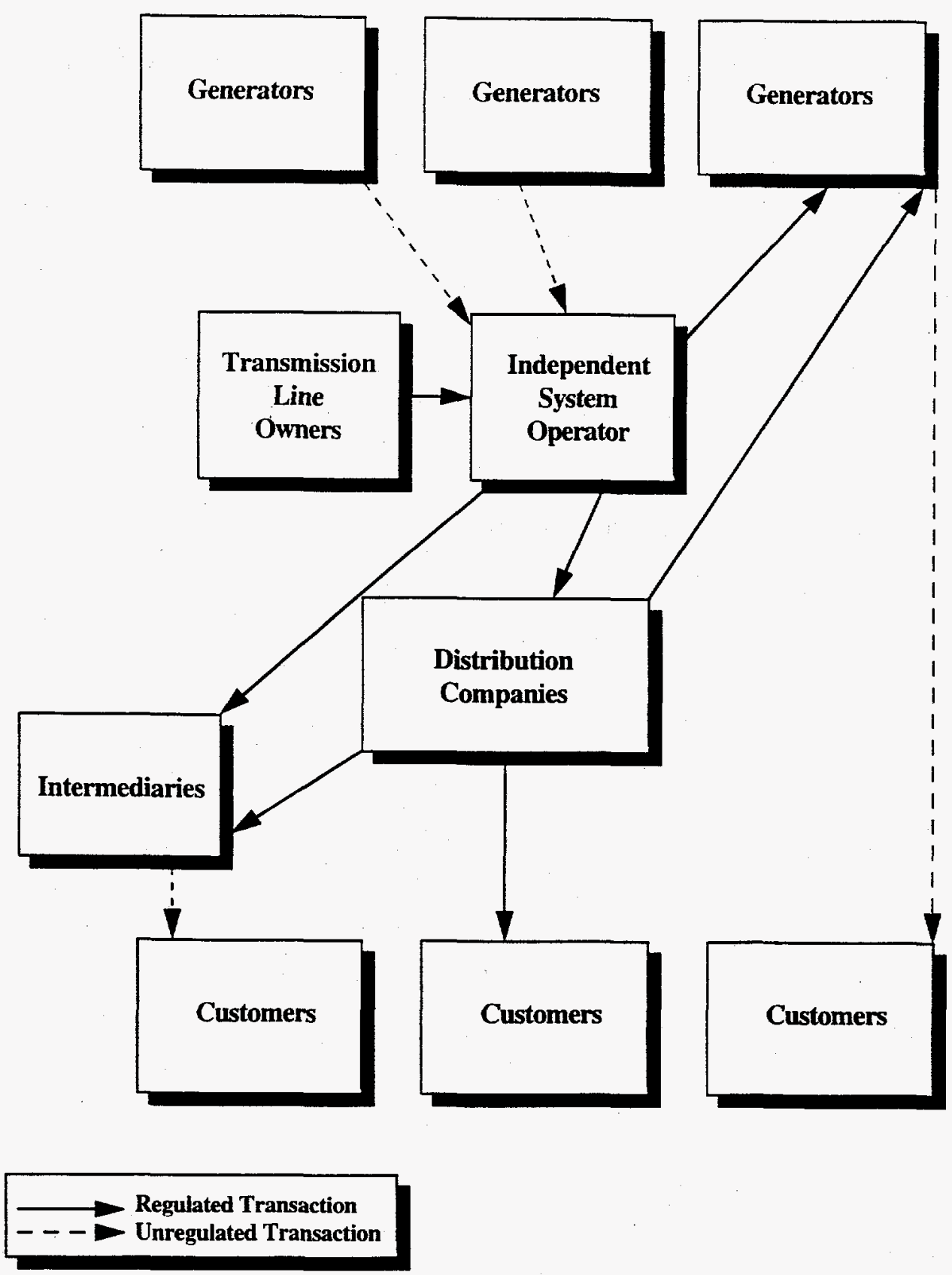


these transactions is not regulated. ${ }^{4}$ Under a bilateral contract, however, generators must purchase transmission and distribution services. FERC regulates the sales of transmission services (i.e., transmission-access charges); state commissions regulate distribution sales (i.e., distribution-access charges). State commissions also regulate sales made between distribution companies and retail customers. The retail sales of intermediaries are not subject to state regulation. FERC regulates the ISO and TLOs; the nature of that regulation depends on the institutional relationship between the ISO and TLOs (to be discussed below).

\subsection{Market Design Issues}

The restructured market characterized in Figures 5 and 6 contains the necessary institutions to foster a workably competitive electric market. ${ }^{5}$ Poorly designed institutional features of this market, however, can affect incentives, conduct of market participants, and result in higher electric supply costs than if the features were designed differently. In large part, these market-design features are manifestations of the special characteristics of producing and delivering electric energy and the need to create special market-enhancing institutions. We discuss five such features: (1) ownership of the vertical stages of the industry (functional vs. corporate unbundling); (2) the type of regulation that FERC imposes on the ISO and TLOs (costbased, sales-based, or performance-based); (3) the relationship between the ISO and TLOs (centralized vs. decentralized); (4) decisionmaking on expansion of the grid (the ISO vs. individual TLOs vs. transmission users); and (5) consolidation of control areas (single vs. multiple control areas operated by the ISO).

\subsubsection{Functional vs. Corporate Unbundling}

Requiring vertical divestiture (corporate unbundling) of electric utilities is one way to facilitate competition. Vertically integrated utilities would be required to spin off their generation, transmission, and distribution assets into three separate companies. The new transmission company would be assigned responsibility for operating the grid (or multiple grids

${ }^{4}$ Note here that we are speaking of the economic regulation of price and entry. Other forms of government intervention and regulation would still exist in this restructured market. For example, the construction of any new transmission lines would have to be approved by state siting authorities. A futures market would have to abide by securities and exchange regulations that protect participants in the market. Generators would have to abide by environmental regulations.

${ }^{5}$ In a workably competitive market, no market participant (or group of participants) has monopoly (oligopoly) power on the supply side or monopsony (oligopsony) power on the demand side of the market. In either event, the restructured market would not be workably competitive. 
if control areas are consolidated). Because the new firm owning the transmission assets is legally and financially independent of the generation and distribution companies, it has no incentive to favor one generator over another in a restructured market.

The divestiture of a vertically integrated utility could be into two new companies, instead of three, as long as the transmission (and control) function is in one legally independent company. In Spain, for example, vertically integrated utilities were required to sell their transmission assets to a government entity in 1985 (Kahn, 1996). The government corporation now operates and dispatches a national grid. The former vertically integrated utilities kept their generation and distribution assets. The objective in Spain was to facilitate a competitive electric market. ${ }^{6}$

In its rulemaking on transmission access, FERC requires that utilities under its jurisdiction functionally unbundle generation and transmission facilities to prevent self-dealing and ensure open access to the transmission system. To comply with FERC's rulemaking, vertically integrated utilities can simply reorganize into separate generation, transmission, and distribution subsidiaries. Divestiture of generation, transmission, and distribution assets into three separate companies is not required under FERC's rulemaking or other federal legislation or policy.

Divestiture and functional unbundling are not economically equivalent. Assuming that generation is deregulated and transmission and distribution are not, divestiture and functional unbundling do not provide the same incentives for participants in the market at the generation, transmission, and distribution stages and will not necessarily lead to equally efficient outcomes. Under functional unbundling, utilities have an incentive to allocate more fixed costs to regulated stages than to deregulated ones. Under divestiture, this incentive does not exist.

Because generation is not regulated and transmission is, a functionally unbundled utility has an incentive to misallocate common costs between the generation and transmission stages. The regulatory commission does not know the cost structure of the utility in detail and, therefore, allows the cross-subsidization to occur. The misallocation increases the revenue requirement of the TLO, resulting in lower generating costs.

Over the longer term, organization into three subsidiaries of one utility rather than three separate companies could also affect the selection of generating technologies by the utility. If a utility is able to allocate a large portion of the fixed costs of a technology to a downstream regulated stage of the industry such as transmission or distribution, it will be able to lower its costs in the unregulated, generation stage of the industry. Under functional unbundling,

${ }^{6}$ Unfortunately, the market-facilitating role of the government corporation has been politicized to give preference to generators using indigenous Spanish coal in the dispatch of generators in the bulk power system (Kahn, 1996). 
therefore, the utility has an incentive to select technologies that may be competitive in generating markets due in large part to cost misallocation, but does not minimize total system costs.

It is also possible for a functionally unbundled utility to cross-subsidize two regulated stages. Consider, for example, FERC-regulated transmission transactions and state-regulated distribution transactions. Assume that FERC uses COSR for the ISO's transactions and state commissions use a performance-based approach for distribution transactions. To the extent there are fixed costs shared between the transmission and distribution stages, there is an incentive for a functionally unbundled utility to allocate more costs than economically justified to the transmission stage because prudently incurred costs are recouped on a dollar-for-dollar basis under COSR. The incentive under PBR is to cut costs and increase profits or, in this case, to allocate less costs to the distribution stage.

Finally, the possibilities for cross-subsidization by functionally unbundled utilities are not limited exclusively to subsidies between vertical stages of the industry. A functionally unbundled utility could cross-subsidize within stages. For example, if the markets or contracting process for one or more ancillary services were not perfect, a functionally unbundled generator could allocate higher costs to the production of ancillary services than to the supply of real power. Again, the costs allocated to the competitive portion of the market would be lower than economically justified.

\subsubsection{Ratemaking and the ISO}

As in current restructuring proposals, assume that the ISO is a separate corporation, unaffiliated with ownership interests in other stages of the industry. It is formed exclusively to operate the grid. Assume it is also a non-profit corporation. Its assets are those necessary to perform the grid's control function, limited to office space, computer capabilities, and the like. Its employees are limited to those performing this control function.

Initially, further assume that one or more TLOs--depending on the design size of the market--consign decisionmaking responsibility for both operations and expansion of the grid to the ISO. That is, decisionmaking on all aspects of transmission and control of the grid is centralized within the ISO.

This decisionmaking responsibility covers short-run operating and maintenance decisions. The ISO makes everyday decisions on switching circuits, re-dispatching the grid, and performing maintenance. Employees of the TLOs continue to function as TLO employees, but all decisions are made by the ISO. The TLOs simply implement the orders of the ISO.

The ISO also makes decisions that affect the long-run. The ISO decides when to expand

the grid to ensure reliability as more customers come on the system and when to expand the grid 
to relieve congestion. In the event that the grid is expanded, the additional lines are, of course, the legal property of the TLOs.

The ISO controls access to the grid and collects fees from users of the grid under a single tariff filed with FERC. From these revenues, the ISO pays its own expenses and the operating and capital expenses of the TLOs. The ISO's revenues include: (1) fees to use the transmission system (a transmission access charge) for those users whose customers are located within the ISO-controlled grid; (2) a wheeling access charge for users of the system whose buyers are outside of the ISO-controlled grid; (3) usage charges (congestion charges) to compensate the ISO for use of the system when there is a capacity shortage; and (4) fees for ancillary services.

A centralized relationship between the ISO and TLOs obviates the need for FERC to regulate the TLOs individually. The ISO simply acts as an agent for the TLOs for ratemaking purposes. FERC regulates the ISO and the ISO allocates its revenue to each individual TSO based on the TLO's investment and operation and maintenance costs.

Historically, FERC has used COSR for the wholesale coordination and requirements transactions of utilities under its jurisdiction. Coordination transactions are those in wholesale spot markets; requirements transactions are made for firm commitments of power on a long term basis. Although requirements transactions between IOUs and wholesale purchasers of electricity are still cost-based, FERC has allowed prices of coordination transactions to become marketbased in recent years. Wheeling transactions under tariffs filed in response to FERC's Order No. 888 may also be market-based.

Under this centralized relationship between the ISO and TLOs, cost-based ratemaking may not provide the ISO proper incentives to carry out its responsibilities efficiently. For example, what incentives does an ISO have to make efficient investments under COSR when it can pass along all prudently incurred costs in the ratemaking process? Even if it wanted to make efficient investments, it is unlikely that the ISO would have sufficient information to do so. Efficient investments require comparing the costs of transmission congestion with the cost of the investment, information that the ISO would not necessarily have. Assuming that FERC has authority to set rates on a basis other than costs, a form of ratemaking other than that based on cost-of-service may be more effective.

Because one of the ISO's important objectives is to maximize throughput on the grid, an alternative to COSR is return-on-output ratemaking. Under this form of ratemaking, FERC ties the profits of the TLOs--through the ISO--to sales, rather than investment as in COSR. The ISO can choose the amount of inputs and outputs it desires, but is not allowed to earn profits beyond a fair return per unit of output. FERC sets the return on output. Bailey (1973) showed that returnon-output ratemaking provides a utility incentives to choose an economically efficient amount of inputs for any level of output. By setting the return on output sufficiently low, FERC can also induce the utility to expand its output more than when the allowed return is higher. 
Another alternative is return-on-revenue ratemaking. If marginal revenue on each sale is positive, the utility theoretically behaves the same as under return-on-output ratemaking. It uses inputs efficiently at each level of output. However, recalling that the ISO has responsibility for investment decisionmaking, will it seek to make efficient investments under return-on-revenue ratemaking when capital investments reduce congestion on the grid and, therefore, the ISO's revenues?

A third alternative to COSR is PBR. FERC could cap the average revenue (i.e., price) that the ISO is allowed to receive. This average revenue can then be indexed to a measure of inflation. The ISO's average revenue would not be allowed to exceed the cap. The ISO's incentives then are to cut costs and to retain as much profit as possible for itself and the TLOs.

But does the ISO really have an incentive to cut costs under PBR? Developing innovative ratemaking approaches for the ISO may be fruitless because of property rights. By design, the ISO is a firm independent of any other ownership interests in the industry. This is to ensure that the ISO will not discriminate against any participants in the market. However, because it does not own the transmission facilities, property rights theory suggests that the ISO's incentives to behave efficiently or to otherwise maximize the discounted net stream of revenues of TLOs--whose systems the ISO is operating--are limited. Attempts by FERC to induce profitor wealth-maximizing behavior on the part of the ISO under this centralized relationship between the ISO and TLOs will probably be frustrated because of property rights. The challenge for policymakers is to devise more decentralized arrangements between the ISO and TLOs.

\subsubsection{Decentralized Relationship between the ISO and TLOs}

The only limit to the working relationship between the ISO and TLOs is the creativity of the parties establishing the relationship. The only constraint on that creativity is FERC which must approve the contracts, protocols, and tariffs of the ISO and TLOs. The key ingredients of any agreement between the ISO and TLOs are day-to-day responsibilities of the parties in the short run and system planning and expansion in the long run. FERC decides on the type of regulation it will impose on the parties.

One decentralization alternative is to bid out a management contract for the ISO, providing incentives for the winning contractor to minimize total costs of bulk power operations. The responsibilities of the contractor would be limited exclusively to day-to-day control of the grid and spot market. All other transmission functions would remain with TLOs. TLOs would be responsible for decisionmaking on expansion of the grid, maintenance of the grid, and

\footnotetext{
${ }^{7}$ Under a nodal pricing system, transmission-line owners earn revenues from line losses and congestion.
} 
revenue-collection. Each TLO would submit its own tariffs for approval by FERC. TLOs would compensate the ISO for running the grid and spot market.

Two efficiency-related questions arise under these types of arrangements. First, assuming that the ISO, operating under a management contract, does not discriminate against potential users of the grid, what kind of incentives do you provide a contractor to ensure efficient operation of the grid? Equal access is only one of an ISO's many responsibilities.

Second, under this decentralized relationship between the ISO and TLOs, how does one ensure that the investment decisions of the TLOs will not be self-serving for a functionally unbundled TLO? A TLO that owns generating plants has an incentive to construct transmission lines that will favor the dispatch of its own generating units. Strategically placed transmission lines in a grid can favor the generating units of one owner at the expense of others by creating congestion in portions of the grid.

Alternatively, corporately unbundled (divested) TLOs with expansion responsibility may have an incentive not to construct transmission lines when congestion arises because, as noted, congestion is one source of revenues for a TLO. In this circumstance, ratemaking by FERC plays a pivotal role.

\subsubsection{Decisionmaking on Expansion of the Grid}

Given that TLOs acting alone in a functionally unbundled market do not have proper incentives for making efficient investments, another mechanism must be developed to expand the grid when it is economically efficient to do so. One option is to decentralize decisionmaking, allowing users of the grid to make transmission investments. If the estimated cost of increasing the capacity of the grid is less than the foregone cost of not having desired capacity on the grid, it would be economically attractive for users to expand the grid efficiently.

Hogan's (1992) system of TCCs is an example of a grid expansion mechanism based on decentralized market principles. Assuming a nodal pricing system, the ISO's revenues come from two sources: system losses and congestion. Hogan's TCCs hinge on the congestion revenues that the ISO receives. These revenues would be allocated to holders of TCCs between two points on the grid. A TCC is a financial right, not a physical right. Holders of the contracts are entitled to financial compensation when the grid is congested; the ISO does not provide the holder a physical right to move electrons through the network.

Users who do not have enough financial congestion rights and want to reduce congestion have an incentive to expand the grid. The financial benefits of investing in new transmission capacity are given to the investor and, therefore, the investor has an incentive to expand capacity. The incremental benefits of expanding the grid are defined as the difference between two 
dispatches of generating units on the grid. Because a minimum-cost dispatch is not unique, the investor has the option of selecting the dispatch used to determine his financial payments under a TCC.

If a Hogan-type market-based expansion is too cumbersome and exclusive responsibility for expansion by the ISO or TLOs results in inefficiencies, policymakers could divide decisionmaking responsibility on grid expansion among two or more parties. For example, the three parties to the ISO filing in California suggest that decisionmaking on grid expansions be divided into "economic" and "reliability" components. Reliability investments are those made because of demand growth; economic investments are those made for market access. The TLOs make reliability decisions and the users of the grid make the economic ones (Pacific Gas and Electric Company, San Diego Gas and Electric Company, and Southern California Edison, 1996). One possible problem with this approach is distinguishing between the two types of investments.

\subsubsection{Consolidation of Control Areas}

As discussed in Chapter 2, there are 138 control areas in the United States (146 in the North American bulk power system). Because an ISO performs functions similar to the operator of a control area, 138 ISOs could theoretically be created to operate U.S. electric markets. Alternatively, control areas could be consolidated in an attempt to reduce operating costs (e.g., computer equipment, office buildings). California, for example, proposed consolidating the control areas of its three major investor-owned utilities into one (Pacific Gas and Electric Company, San Diego Gas and Electric, Southern California Edison, 1996).

Efficiency considerations in consolidating control areas are important. Will the consolidation of control areas result in lower costs? Are there economies of scale in operating a bulk power system? To guide policymakers in consolidating control areas, what is the minimum efficient scale of a bulk power system? Are there diseconomies of scale beginning at some critical level of output?

Unfortunately, answers to these questions do not exist. They await statistical analyses of the cost structure of bulk power systems.

\subsection{Loss of Vertical Economies and Other Costs}

The system operator in each of the 146 North American control areas has the necessary information and control mechanisms to instantaneously balance generation and load at minimal 
costs for its area. If the system operator dispatches power plants in a vertically integrated system, he has an incentive to favor his own units at the expense of others trying to gain access to the grid. As discussed earlier, creating an operator independent of ownership in the system is one solution to the access problem. An ISO would facilitate both intra- and inter-area trade on the system, at the same time performing the unit commitment and dispatch responsibilities of the control area.

Ideally, the ISO would function in a manner similar to the system operator in a vertically integrated utility, optimizing short- and long-run performance of the system. In practice, this may not occur because of differences in incentives and information in the two market structures.

In the remainder of this section, we review potential efficiency losses attributable to creation of an ISO. The comparison is between a vertically integrated structure and one centered around an ISO as depicted in Figure 5. In large measure, the potential efficiencies sacrificed in the restructured market are those attributable to vertical coordination in existing markets. In Chapter 2, we discussed vertical economies in the aggregate and, although sketchy, the empirical evidence indicates they could be substantial. Here, we discuss them in greater detail.

\subsubsection{Transaction Costs}

In an economically integrated network with the same utility owning generation, transmission, and distribution assets, transaction costs are minimal. At each downstream stage in the structure, the utility receives the output of the preceding stage at an internal transfer price. Acquiring the necessary information to make informed decisions about markets is nominal in a vertically integrated utility.

The electric industry is currently dominated by these types of internal transfers. In 1994, for example, nearly 80 percent of the sales of investor-owned utilities were self-generated (Edison Electric Institute, 1995), indicating that utilities relied a great deal more on internal transfers than on market transactions to procure real power and ancillary services for their delivery systems. This will change dramatically in restructured electric markets with a corresponding increase in transaction costs.

For wholesale and retail customers, obtaining TCCs, contracts for differences, or participating in spot and futures markets is not costless. As retail customers seek out alternative suppliers of electricity, their transaction costs will increase, and the increase will be disproportionate among customer classes. At one extreme, the transaction costs of high-volume customers such as industrial ones are a small fraction of their total electric bill. At the other extreme, transaction costs for residential customers are significantly higher as a percentage of their electric bills. Extending beyond transaction costs, some customers such as low-income ones do not have the ability to shop around for alternative power suppliers. This has equity 
implications.

The transaction costs of distribution companies will also increase. In existing vertically integrated markets, distribution assets are simply extensions of--and, in many cases, indistinguishable from--the transmission system. In a restructured market, distribution companies perform two functions, both of which are independent of the transmission system. In their transport function, they serve as local distributors of electricity on a non-discriminatory basis for anyone willing to pay for the service. In their market function, distributors compete with intermediaries such as marketers, aggregators, and brokers for retail load. In this latter role, distribution companies must procure power supplies that are competitive with the supplies of intermediaries to retain their market share, increasing transaction costs in the process.

The transaction costs of the ISO will also be higher than those of the system operator in a vertically integrated market. The creation of a spot market for electricity requires that the ISO aggregate demand bids and solicit and procure real power from generators offering such services in the market to match loads.

The process of procuring ancillary services independent from real power will also increase transaction costs, irrespective of the manner in which those services are procured. In existing electric markets, all generating services such as real power, reactive power, and other reserves are bundled together and priced together. In the restructured market, generators must separately identify the costs of each of the services and price them accordingly. If the services are sold in competitive markets to the ISO, or any wholesale or retail customers willing to procure them independently of the ISO, generators compare their marginal supply costs with the market price. If the services are procured by the ISO through contract, generators must still identify the costs of providing the service. If ancillary services are priced by fiat of the ISO, transaction costs still will increase.

\subsubsection{Operating Costs}

Unbundling electric services and providing ancillary services separately may result in higher costs for reasons other than increases in transaction costs. Currently, individual power plants provide ancillary services jointly with real power. Are different ancillary services less costly when produced by different generating units in a system? Are there economies of scope in producing real power, reactive power, and other ancillary services? Are these economies at the unit level? The plant level? The control area level? Or, can each generating service be unbundled, priced separately, and produced at the same or lower cost than when the services were produced jointly?

These questions await applied studies. To our knowledge, no studies have been conducted on the relationship between the costs of supplying real power, reactive power, 
frequency control, and other reserves such as spinning and supplemental reserves in an electric power system.

As a practical matter, the costing and pricing of ancillary services may be an important issue. Kirby and Hirst (1996), for example, estimated the costs of ancillary services for 12 electric utilities that produce more than a quarter of U.S. electric output. On average, ancillary services account for 10 percent of the total generation and transmission expenses of the utilities-or, $0.414 \phi / \mathrm{kWh}$. The percentage ranges from five to 25 percent for the 12 utilities. On the low end, then, ancillary services may not be a significant factor in generation costs. On the high end, however, they will be. ${ }^{8}$

Assume that generators, distributors, and other market participants operate efficiently in the restructured market, responding appropriately to short-term price signals and contracting accordingly over the long term. If the stages in a vertically integrated electric system were totally distinct with no substitution possibilities among them, an ISO could independently operate the system efficiently if it were given the appropriate incentives to do so. The ISO could minimize both short- and long-run costs.

There are, however, many substitution possibilities between different stages of the industry that, if the whole system were not optimized jointly, could lead to higher real costs in a restructured market than in a vertically integrated one. A vertically integrated utility that owns generation, transmission, and distribution facilities and dispatches its own units may have the information and incentive to minimize system costs more than an ISO whose information may be limited and incentives may be different.

The possibility of substituting transmission lines for power plants--or power plants for transmission lines--is an important substitution example. A strategically placed power plant on a grid may substitute for transmission capacity. A strategically placed power line can substitute for a power plant. In a vertically integrated system, the planning function encompasses the three vertical stages. Assuming that the ISO has responsibility for making investment decisions for the grid, will it optimize over generation and transmission? Or, will it only consider the transmission portion if congestion is present? Will the operator of a divested grid make the most efficient investment decisions? Or, does it have the same incentives as the ISO?

Supplying reactive power is another example in which there are substitution possibilities between stages. Power plants or components of the transmission system such as capacitors and

${ }^{8}$ Applying the 10 percent estimate to the entire industry, ancillary services cost $\$ 12$ billion in 1994. Taken as a whole, system reserves--load following, reliability, and supplemental operating reserves--are the most expensive ancillary service $(0.177 \mathrm{c} / \mathrm{kWh}$ or 43 percent of the total). Compensating for real-power losses is the single-most expensive ancillary service $(0.122 \mathrm{c} / \mathrm{kWh}$ or 30 percent of the total). 
static var compensators can provide reactive power. The capital costs of the transmission-system components is much less than the capital costs of generating units. What incentive does the ISO have to make the optimal choice between power plants and transmission components?

Assuming that the ISO is totally independent of the other three stages of the industry, decisionmaking on all transmission activities is centralized at the ISO, and the ISO can recover all prudently incurred costs (COSR), the ISO may be financially indifferent to the selection of power plants and transmission components and, therefore, attempt to minimize costs. However, assume that the ISO is subject to PBR and there is an incentive for it to cut costs. Three questions are relevant:

- Will the ISO have an incentive to have reactive power supplied by generating units rather than transmission components, even if the selection of transmission components would reduce costs without sacrificing reliability?

- Does the nature of the relationship between the ISO and TLOs (centralized vs. decentralized) provide different incentives for the ISO when making this decision?

- Does the fact that the ISO operates the bulk power system but does not own any part of it (i.e., property rights considerations) change incentives for this decision, irrespective of the relationship between the ISO and TLOs and the form of ratemaking imposed on them?

Besides substitution possibilities, there are important coordination requirements between generation and transmission. Will they be conducted at minimum cost? Maintenance of generating units is an example. In a vertically integrated grid, shutting down and performing maintenenace on each generating unit is scheduled periodically, consistent with expected loads on the system. Will maintenance be scheduled properly in the restructured market?

There are also substitution possibilities between the transmission and distribution stages. For example, appropriately placed transmission delivery points or nodes will eliminate the need for some distribution requirements. The same issue arises here as in the generation-transmission substitution possibilities. Will the decisionmaking be coordinated between the ISO, TLOs, and distribution owners?

\subsubsection{Administrative Costs}

The costs of the control function performed by the ISO should be higher than the costs of control in existing electric markets. First, there are more participants in the restructured market, either selling generating services to the ISO, paying for transmission services, or purchasing 
power from the spot market. More participants translates into more transactions and higher administrative costs. Second, in the event that a system of TCCs is created, the ISO would more than likely administer it. Other than the costs of keeping track of financial payments under a system of TCCs, there is a potential for higher costs to resolve disputes on payments, the value of the financial payments in the event of investments to expand the grid, and the like.

A significant portion of the administrative, general, and sales expenses of electric utilities is fixed and relates jointly to the three stages of the industry. These classes of expenditures could increase in a restructured market. For example, if the three stages were divested into three separate companies, these expenditures will probably increase in total because of the economies associated with vertical integration. Assuming functional unbundling rather than divestiture, the expenditures could also increase for the regulated transmission and distribution stages because of the incentive to cross-subsidize unregulated portions of the market (see discussion above).

\subsection{The Costs of Regulation}

The complexity and costs of regulation and ratemaking in the U.S. electric industry mirrors the complex, decentralized relationships among (1) investor-owned utilities, (2) municipal, county, and state systems, (3) rural electric cooperatives, and (4) federal utilities. Each of these ownership types is represented to varying degrees in different regions of the country, and each of them is regulated in different ways at different levels of government. If the restructured market shown in Figure 5 is representative of every electric market in the country, each of these ownership types will be influenced dramatically by restructuring. Consequently, federal, state, and local regulation will be affected. FERC will be affected the most.

Ironically, the costs of regulation may actually increase in "deregulated" markets such as the one depicted in Figure 5..$^{\circ}$ This will almost certainly be true in the short term as federal and state regulatory responsibilities are sorted out, transition costs are resolved, oversight of new types of transactions begins, and regulation of new institutions such as the ISO evolve. But regulatory costs may also be higher in the medium to long term because of the necessity to adjudicate complaints on such things as access, cost shifting, and congestion contracts; to ensure adequate capacity of the transmission system; and the like. The extent of these cost increases in the long run depends in large measure on the nature of the institutional relationships established in the market; the type of unbundling (functional vs. corporate); the nature of the relationship between the ISO and TLOs; ratemaking for the TLOs and ISO; and decisionmaking about expansion of the grid.

${ }^{9}$ Regulatory costs include the costs incurred by regulatory commissions and regulation-related costs incurred by utilities and other participants in the market. 
FERC's regulatory responsibilities will increase and so probably will the costs of regulation at the federal level. In wholesale markets, FERC currently regulates two types of transactions made by investor-owned utilities: ${ }^{10}$ coordination transactions (spot market sales between utilities) and requirements transactions (firm sales between investor-owned utilities and other owners). These types of transactions currently account for approximately one fifth of all wholesale transactions. The remainder of IOUs' wholesale transactions are not regulated because they are internal transfers through vertically integrated utilities; they are not market transactions. In restructured electric markets, virtually all transmission-related transactions will be in markets and, therefore, under FERC's jurisdiction.

The relationship between the number of transactions under FERC's jurisdiction and regulatory costs is not necessarily proportional. However, the relationship is not necessarily totally inelastic either. And, other features of restructured markets tend to increase regulatory costs. First, FERC has ultimate jurisdiction over two new institutions created to enhance the functioning of the market: the spot market and the ISO. Second, regulatory jurisdiction over retail wheeling transactions is a potential source of contention between FERC and the states. In the short run, this increases administrative and legal costs for both FERC and state commissions; in the long run, it could increase oversight costs.

State regulatory commissions will continue to have jurisdiction over distribution companies and state planning offices will continue to have jurisdiction over the siting of new generation and transmission facilities. Commissions will have a choice of the type of ratemaking they impose on distribution companies. If they choose some type of performance-based approach such as price caps, there is a chance for significant cost savings because full-scale reviews of utilities may occur in five- or six-year increments. However, the comprehensive performance-based plans proposed or currently in existence stop short of limiting performance reviews and rate cases of electric utilities to five- or six-year intervals (Comnes, Stoft, Greene, and Hill, 1995). The costs of state regulation probably will not decrease in restructured markets.

${ }^{10} \mathrm{FERC}$ does not have ratemaking jurisdiction over publicly owned utilities and rural electric cooperatives. However, it does have some authority in facilitating interchanges between investorowned utilities and other forms of ownership. 



\section{Ownership and Efficiency}

\subsection{Background}

From the beginning of the electric industry in 1882, the franchises awarded to firms by municipal governments to generate and distribute electric power were a source of controversy. On one hand, privately owned firms found some of the larger franchises financially attractive and they bid for the franchise accordingly. On the other hand, electric customers of some franchises run by private firms were economically abused by those firms. The biggest debate in the early years of the electric industry was whether electric utilities should be privately owned and subject to economic regulation or publicly owned and subject to the authority of locally elected officials.

The early utilities, whether privately or municipally owned, were monitored at the municipal level. As privately owned electric utilities gained prominence, however, state commissions were created to regulate them. In 1887, Massachusetts was the first state to exert regulatory control over electric utilities. However, it was not until 1907 that any state regulatory commission was empowered to regulate the rates of electric utilities. Between 1907 and 1914, 27 states established regulatory commissions.

Because many of the municipalities offering an exclusive franchise were small and not very attractive to private firms, municipally owned utilities flourished in the early years of the industry. At the end of 1882, there were four municipal electric systems. By the end of 1923, there were 3,083 municipally owned utilities. However, in large part because of the cost savings associated with vertically integrated regional networks and aggressive acquisitions by private firms, the number of municipal systems declined to 1,862 in 1932 (Schap, 1986).

President Róosevelt created the Rural Electrification Administration (REA) by Executive Order in May 1935. Congress enacted it into law in May, 1936 and made it part of the Department of Agriculture in 1939. Originally created as a lending agency to ensure the availability of capital for rural electric cooperatives (RECs) in remote areas, the REA relaxed restrictions on loans for generation and transmission investments in 1961. Presently, there are 939 RECs (Energy Information Administration, 1995).

Federally owned utilities consist of the Tennessee Valley Authority (TVA) and four power marketing agencies. ${ }^{1}$ Congress created TVA in 1933 primarily for flood control and economic development and secondarily as a power agency. Congress created the Bonneville

\footnotetext{
${ }^{1}$ The Alaska Power Administration, a fifth power marketing agency, is in the process of privatization.
} 
Power Administration (created in 1937), Southwestern Power Administration (1943), Southeastern Power Administration (1950), and Western Area Power Administration (1977) to market electric energy produced at federal generating facilities.

State-owned utilities were created for similar reasons. The New York Power Authority, for example, was created in 1931 to distribute power produced at the St. Lawrence River Project. The South Carolina Public Service Authority was created in 1934 to construct and operate the Santee-Cooper hydroelectric project. Other states with large power agencies include Texas (Lower Colorado River Authority), and Arizona (Salt River Project).

Today, investor-owned utilities (IOUs) dominate publicly owned utilities (POUs) and RECS, accounting for more than three-quarters of the industry in terms of capacity and sales. However, the ownership structure is changing.

At one level of change, privately owned, non-utility generators currently construct more than one-half of the new generating capacity in the industry. This trend is likely to continue in the future.

At another level of change, private vs. public ownership is part of the restructuring debate. On one hand, many industry observers are calling for Congress to privatize TVA and the power marketing agencies (Bonneville, Western, Southwestern, and Southeastern). Besides providing revenues for the federal treasury, the sales would end subsidies to the federal utilities and allegedly improve the efficiency of the industry (to be discussed below). On the other hand, many industry observers are calling for local policymakers to municipalize distribution systems to give captive customers of IOUs more market power in restructured electric markets that allow direct access of retail customers to electric suppliers. By owning the local distribution facilities, customers will be able to pool their buying power and, as a group, shop around for power at rates cheaper than they now obtain from their investor-owned supplier.

In deciding on the merits of either privatizing federal utilities or municipalizing local distribution facilities, policymakers should consider, among other factors, the relative efficiency of publicly vs. privately owned utilities. After looking at current ownership of the industry in the next section, we explore the relative efficiency of private and public utilities in Section 3. We then discuss possible effects of ownership on the efficiency of restructured electric markets in Section 4.

\subsection{Diversity of Ownership}

The United States has one of the most decentralized and diverse electric power sectors in the world. The sector consists of electric utilities, non-utility electric generators (NUGs), and net 
imports of electric energy from Canada and Mexico. As the industry goes through a transition in the coming years, these three supply sources of electric energy will not change. However, their significance (percentage contribution) and relationship with each other and new participants in electric markets such as marketers and aggregators (the structure of the industry) will change dramatically in many parts of the country.

Currently, electric utilities account for 92 percent of capacity in the industry $(745,954$ megawatts). NUGs account for the other eight percent $(65,010 \mathrm{MW})$. On an incremental basis, however, NUGs have accounted for more than 50 percent of capacity additions in the industry for the past eight years. That trend will likely continue in the future.

There are 3,212 electric utilities either (i) privately owned with shares traded on stock exchanges, (ii) publicly owned by the federal government (TVA and power marketing agencies), (iii) publicly owned by subnational governments (i.e., state, county, or city-owned), or (iv) cooperatively owned by RECs. In terms of capacity, sales, and revenues, privately owned utilities dominate the U.S. industry.

Table 2 shows the total amount of generating capacity owned by electric utilities at the end of 1994. The data are further disaggregated by generating technology. Geothermal and biomass technologies are included as part of conventional steam generation in the data. By including only the amount of capacity for electric utilities in Table 2, we exclude $65,010 \mathrm{MW}$ of capacity owned by NUGs.

The data in Table 2 show that IOUs own more than three-fourths of the generating capacity of electric utilities. No other form of ownership accounts for more than 10 percent of total capacity. By technology, IOUs dominate ownership of conventional and nuclear steam plants. Because of the large amount of hydropower owned by TVA, the U.S. Army Corps of Engineers, and the Bureau of Reclamation, federal utilities account for nearly one-half of total U.S. hydraulic capacity. Municipal utilities own more than one-third of the internal combustion capacity, even though they account for less than six percent of total capacity. 
Table 2

U.S. Electric Generating Capacity

By Ownership Type

1994

Ownership

Convent'l Internal

Steam Combustion Nuclear Renewable Total

Total (MW)

537,884

9,871

107,857

90,343

745,954

$\%$ Composition:

Investor-Owned

82.0

6.0

61.0

90.4

35.7

0.0

33.3

6.6

77.1

District, State

3.4

0.4

4.1

15.1

5.6

Federal

3.8

0.0

5.5

44.6

4.9

Cooperatives

4.8

3.0

0.0

0.4

8.9

3.5

Total

100.0

100.0

100.0

100.0

100.0

SOURCE: Edison Electric Institute (1995).

\subsection{Relative Efficiency Between Ownership Types}

\subsubsection{Differences among IOUs, POUs, ${ }^{2}$ and RECs}

Property rights theory suggests that investor-owned firms that are either closely held or have their shares traded on stock exchanges are more efficient than publicly owned firms. Diffusion of ownership is an important reason for this hypothesis.

${ }^{2}$ Throughout the remainder of this chapter, POUs refer to those utilities owned by cities, counties, states, and the federal government. We refer to the specific type of POU when relevant to the discussion. 
Ownership of investor-owned firms is concentrated among fewer individuals than publicly owned firms. These individuals have an incentive to monitor the performance of the firm's managers to ensure that costs are controlled and profits are enhanced. Ownership of publicly owned firms is much more diffuse because all citizens of government entities such as cities, counties, and states own public firms. Individual owners are not allowed to sell shares in public firms. The only way to divest ownership in a municipally owned utility, for example, is to move out of the city that owns the utility. The incentives for monitoring the management of a publicly owned firm differ from those of a privately owned firm. Excluding the electric industry, statistical studies of the efficiency of private vs. publicly owned firms tend to corroborate property rights theory.

To test hypotheses of property-rights theory for electric utilities and determine if one form of ownership is more efficient than another, factors that differentiate forms of ownership must be taken into consideration. Three are important: (1) regulation (and, therefore, the incentives and strategies of different utilities); (2) input costs; and (3) size, structure, and system operations. We discuss each in turn.

Regulation. IOUs are subject to profits restrictions under price regulation. Historically, cost-of-service ratemaking (COSR) in which a utility is compensated dollar-for-dollar for its prudently incurred costs was the mechanism used by most state commissions to restrict profits. In recent years, this regulatory model has been changing. With competition imminent in many electric markets along with a ratemaking model that restricts a utility's flexibility to meet its competition, state regulatory commissions are increasingly using performance-based ratemaking (PBR) instead of COSR (Comnes, Stoft, Greene, and Hill, 1995). PBR severs the relationship between costs and prices, giving utilities more incentives to reduce costs and the flexibility to set prices to meet those of their competitors (Hill, 1995).

Publicly and cooperatively owned utilities are not generally subject to the same type of regulation as IOUs. Even in the limited number of states in which POUs and RECs are regulated by state commissions, they are not regulated in the same manner as IOUs. For example, a return on rate base is generally not part of the regulatory framework for POUs and RECs. A common financial constraint shared by POUs is the requirement to be financially sound to attract financing from capital markets. An important objective in setting rates then is to generate a sufficiently high interest coverage ratio. Lenders give the greatest weight to the growth potential of local economies and the interest coverage ratios of publicly owned firms in evaluating lending risks. By policy of the Rural Utilities Service (the successor to the Rural Electrification Administration), the managers of RECs are also required to generate a sufficiently high interest coverage ratio (Hill, 1988).

Regulation of IOUs complicates property rights theory. By subjecting the earnings of a utility to profit regulation, regulators weaken the owners' property rights in the utility. In regulated firms that are privately owned, owners may not be as vigilant in monitoring the cost and profit performance as they would be in a privately owned, non-regulated firm. 
Differences in regulation must be accounted for in evaluating the relative efficiency of public and private electric utilities. If they are not, observed differences in efficiency may not be due to property rights but due to behavior induced by different forms of regulation.

Input Costs. POUs and RECs have access to relatively less expensive sources of debt financing than IOUs. City- and state-owned electric utilities issue tax-free bonds at lower rates of interest than IOUs can obtain in competitive bond markets. RECs have access to debt that is guaranteed by RUS. Also, POUs and RECs are generally exempt from federal income taxes. However, POUs and RECs are either subject to sub-federal taxation or make in-lieu-of-tax payments to counties in which they operate. Although not subject to federal income taxes, TVA, for example, contributes five percent of its previous years revenues to counties in the seven states in which it operates. IOUs can defer a portion of their federal income taxes. POUs and RECs have preferred access to relatively cheap electric energy produced at federal generating plants.

Because resource efficiency is measured in terms of costs, failure to account for differences in input costs when comparing the efficiency of public and private utilities will lead to inaccurate results.

Size, Structure, and System Operations. The forms of ownership vary substantially in size, how they are organized, and how their end-use customers are served. The typical investorowned electric utility is large in comparison with POUs and RECS, and is typically vertically integrated from generation through transmission and distribution. The typical municipally owned utility is small and is exclusively a distributor. Similarly the majority of RECs are also exclusively distributors. A small minority are engaged in generation and transmission. Federal utilities are involved in generation and transmission. TVA owns generation and transmission facilties, while the power marketing agencies transmit electric energy produced by other federal agencies.

Even when POUs and RECs own generation and transmission facilities, they do not necessarily control them. Many POUs and RECs have their power dispatched by IOUs. The POUs and RECs simply need the transmission capability to link their plant to an existing grid. Of the 138 U.S. control areas, only 39 are run by city, county, and state utilities and only 15 by RECs.

These physical and operating characteristics of the industry could account for differences in costs among different ownership types. Failure to account for differences in size, structure, and operations of electric facilities may bias results in comparing the efficiency of IOUs with POUs and RECs. 


\subsubsection{Studies of Relative Efficiency}

The challenge for those attempting to determine if one form of ownership is more or less efficient than another is to account adequately for differences in regulation, input costs, and operations among the ownership types. If one form of ownership exhibits higher costs than another, one cannot determine the source of differences without adequately accounting for these three fundamental differences between ownership forms. Are higher costs due to more costly inputs? Regulation and ratemaking? System characteristics? Or, as property rights theory suggests, diffusion of ownership shares? Unfortunately, existing statistical studies of ownership and efficiency do not adequately account for these differences among ownership types.

Table 3 lists 13 econometric studies conducted over the past two decades comparing the resource efficiency of IOUs, POUs, and RECs. The studies are listed in chronological order based on their publication date. The table includes ownership forms (IOUs, POUs, or RECs); the stages of the industry under consideration (generation, transmission, and distribution); the years of data used in the study; the estimating technique; and major conclusions on the efficiency of ownership types.

To our knowledge, the 13 studies exhaust the list of relative efficiency studies in the last two decades. The table does not include other efficiency-related studies. ${ }^{3}$

The early studies compare IOUs and POUs. POUs were typically municipally owned utilities in these studies. RECs were not analyzed until the study by Hollas and Stansell in 1988. Federal utilities (the federal power marketing agencies and TVA) have not been considered at all.

Seven of the 13 studies address generation exclusively. And, the majority of these studies address conventional steam-electric generation to the exclusion of internal combustion, hydraulic, and nuclear-steam technologies. Only two studies compare ownership in the distribution stage of the industry.

All of the studies are somewhat dated. The most recent study by Koh, Berg, and Kenny uses 1986 data. Of the 13 studies, Berry uses the most recent data (1988) in a study published in 1994.

${ }^{3}$ Some studies consider the efficiency of an ownership type in isolation. Hollas and Stansell (1991), for example, estimated the absolute price efficiency of a sample of rural electric cooperatives. Hollas and Friedland (1980) estimated the effectiveness of regulation of municipally owned utilities. Atkinson and Halvorsen (1980) tested for all types of price inefficiency of investor-owned utilities. Other studies compared aspects of publicly and privately owned utilities other than resource efficiency. For example, Moore (1970) compared the profit-maximizing and actual prices for investor-owned and municipally owned utilities. DeAlessi (1975) compared the selling and purchasing prices of wholesale power for POUs and IOUs. 
Table 3

Summary of Studies Comparing the Resource Efficiency of Ownership Types

\begin{tabular}{|c|c|c|c|c|c|}
\hline Authors (Date) & Ownership ${ }^{a}$ & Stages ${ }^{b}$ & Years $^{\mathrm{c}}$ & Technique & Conclusions \\
\hline $\begin{array}{l}\text { Koh, Berg, Kenny } \\
\text { (1996) }\end{array}$ & $\begin{array}{l}\text { IOU } \\
\text { POU }\end{array}$ & G & 1986 & $\begin{array}{l}\text { Translog } \\
\text { Cost } \\
\text { Function }\end{array}$ & $\begin{array}{l}\text { POUs more efficient at low output; } \\
\text { IOUs more efficient at high output }\end{array}$ \\
\hline $\begin{array}{l}\text { Clagget, Hollas, } \\
\text { Stansell (1995) }\end{array}$ & $\begin{array}{l}\text { POU } \\
\text { REC }\end{array}$ & $\mathrm{D}$ & $1985-89$ & $\begin{array}{l}\text { Cobb-Douglas } \\
\text { Profit (SR) } \\
\text { Function }\end{array}$ & $\begin{array}{l}\text { RECs more absolute price efficient; } \\
\text { POUs more technically efficient }\end{array}$ \\
\hline Berry (1994) & $\begin{array}{l}\text { IOU } \\
\text { REC }\end{array}$ & G,T,D & 1988 & $\begin{array}{l}\text { Translog } \\
\text { Cost } \\
\text { Function }\end{array}$ & IOUs more efficient than RECs. \\
\hline $\begin{array}{l}\text { Hausman, Neufeld } \\
\text { (1991) }\end{array}$ & $\begin{array}{l}\text { IOU } \\
\text { POU }\end{array}$ & $\mathrm{G}$ & $1890 \mathrm{~s}$ & $\begin{array}{l}\text { Non-param } \\
\text { linear } \\
\text { program }\end{array}$ & POUs more efficient than IOUs \\
\hline Cote (1989) & $\begin{array}{l}\text { IOU } \\
\text { POU } \\
\text { REC }\end{array}$ & $\mathrm{G}$ & $1965-73$ & $\begin{array}{l}\text { Cobb-Douglas } \\
\text { Cost } \\
\text { Function }\end{array}$ & RECs more efficient than IOUs \& POUs \\
\hline $\begin{array}{l}\text { Hollas, Stansell } \\
\text { (1988) }\end{array}$ & $\begin{array}{l}\text { IOU } \\
\text { POU } \\
\text { REC }\end{array}$ & G & $1977-80$ & $\begin{array}{l}\text { Translog } \\
\text { Profit (SR) } \\
\text { Function }\end{array}$ & $\begin{array}{l}\text { IOUs more price efficient than RECs; } \\
\text { RECs more price efficient than POUs }\end{array}$ \\
\hline $\begin{array}{l}\text { Atkinson, Halvorsen } \\
\text { (1986) }\end{array}$ & $\begin{array}{l}\text { IOU } \\
\text { POU }\end{array}$ & G & 1970 & $\begin{array}{l}\text { Translog } \\
\text { Cost } \\
\text { Function }\end{array}$ & IOUs and POUs equally price-inefficient \\
\hline
\end{tabular}


Table 3 (Cont.)

\begin{tabular}{|c|c|c|c|c|c|}
\hline Authors (Date) & Ownership & Stages $^{b}$ & Years $^{c}$ & Technique & Conclusions \\
\hline $\begin{array}{l}\text { Fare, Grosskopf, } \\
\text { Logan (1985) }\end{array}$ & $\begin{array}{l}\text { IOU } \\
\text { POU }\end{array}$ & G,T,D & 1970 & $\begin{array}{l}\text { Non-param } \\
\text { Linear } \\
\text { Program }\end{array}$ & POUs slightly more efficient than IOUs \\
\hline $\begin{array}{l}\text { DiLorenzo, Robinson } \\
\text { (1982) }\end{array}$ & $\begin{array}{l}\text { IOU } \\
\text { POU }\end{array}$ & G & 1970-72 & $\begin{array}{l}\text { Multiple } \\
\text { Regression }\end{array}$ & POUs more efficient than IOUs \\
\hline $\begin{array}{l}\text { Pescatrice, Trapani } \\
(1980)\end{array}$ & $\begin{array}{l}\text { IOU } \\
\text { POU }\end{array}$ & G & $\begin{array}{l}1965 \\
1970\end{array}$ & $\begin{array}{l}\text { Translog } \\
\text { Cost } \\
\text { Function }\end{array}$ & $\begin{array}{l}\text { POUs more efficient than IOUs due to } \\
\text { COSR of IOUs }\end{array}$ \\
\hline Neuberg (1977) & $\begin{array}{l}\text { IOU } \\
\text { POU }\end{array}$ & D & 1972 & $\begin{array}{l}\text { Cobb-Douglas } \\
\text { Cost } \\
\text { Function }\end{array}$ & POUs more efficient than IOUs \\
\hline Meyer (1975) & $\begin{array}{l}\text { IOU } \\
\text { POU }\end{array}$ & G,T,D & $1967-69$ & $\begin{array}{l}\text { Multiple } \\
\text { Regression }\end{array}$ & $\begin{array}{l}\text { POUs are more efficient than IOUs where } \\
\text { significant }\end{array}$ \\
\hline Yunker (1975) & $\begin{array}{l}\text { IOU } \\
\text { POU }\end{array}$ & G,T,D & 1969 & $\begin{array}{l}\text { Multiple } \\
\text { Regression }\end{array}$ & POUs are more efficient than IOUs \\
\hline
\end{tabular}

${ }^{2} \mathrm{IOU}=$ investor-owned utility; POU = publicly owned utility (which includes municipal, county, and state systems); REC=rural electric cooperative. Note that federally owned utilities are not compared.

${ }^{\mathrm{b}} \mathrm{G}=$ generation; $\mathrm{T}=$ transmission; $\mathrm{D}=$ distribution

'The years for which data were used in the estimations. 
Finally, the transcendantal logarithmic ("translog") function has generally replaced other functional forms in comparing the cost structures of IOUs, POUs, and RECs. The translog has been used to estimate both profit and cost functions in comparing ownership types. A profit function relates the revenues of a firm to the value of its output and the cost of its inputs. A cost function relates a firms costs to the price of its inputs, the quantity of its outputs, and other relevant explanatory factors. Early studies used simple multiple regression techniques that do not capture the underlying technology or cost structure. The non-parametric linear programming approach used by Fare, Grosskopf, and Logan (1985) and Hausman and Neufeld (1991) imposes less restrictions on the parameters than the other approaches.

The conclusions of the studies do not generally accept the hypothesis of property rights theory that publicly owned firms are less efficient than privately owned ones. In fact, many of the conclusions contradict that hypothesis. However, all of the studies have shortcomings in accurately accounting for the three major differences among IOUs, POUs, and RECs discussed above. Eight comments are relevant.

First, the data may drive some results. The most recent year for data in any of the studies is 1988. The most recent year in which IOUs and POUs were compared is the study by Koh, Berg, and Kenny using 10-year old data. Much has changed in the past 10 years. As utilities change their expectations about the degree of competition, they change their behavior. This is particularly true for IOUs. The regulatory approach toward IOUs has also changed in many states over the past 10 years, allowing them more flexibility in meeting competition and less regulatory oversight.

Second, the properties of the Cobb-Douglas functional form are well known. For example, it places restrictions on the pattern of substitution among inputs used in a production process and the elasticities of substitution for inputs must be unity. The translog is a secondorder approximation to any functional form. As such, it does not place as many restrictions on parameters as other functional forms such as the Cobb-Douglas. The studies by Claggett, Hollas, and Stansell (1995), Cote (1989), and Neuberg (1977) using the Cobb-Douglas must be judged accordingly.

Third, because of the way in which the estimating equations are specified, the studies measure the sources of inefficiency differently. The study by Atkinson and Halvorsen (1986), for example, measures price efficiency, ignoring technical efficiency. ${ }^{4}$ Other studies such as those by Claggett, Hollas, and Stansell (1995) and Hollas and Stansell (1988) measure both price and technical efficiency. Still others were not specified in sufficient detail to isolate the effects of price and technical efficiency. Other studies simply examine the cost of producing a given level of output, ignoring factors that may influence costs. In these studies, the ownership form

${ }^{4}$ Price efficiency and technical efficiency are components of what we call "resource efficiency" in this study. See, for example, Zieschang (1983) for an in-depth discussion. 
with lower costs is more efficient. The studies by Meyer (1975) and Yunker (1975) are examples of this approach.

Fourth, some studies do not include the cost of capital in the cost or profit functions, failing to account for one of the important differences among ownership types. The three multiple regression studies by DiLorenzo and Robinson (1982), Meyer (1975), and Yunker (1975) are examples of studies of this type. Indeed, the latter two studies exclude all input costs. By definition of the short run, the two studies by Clagget, Hollas, and Stansell (1995) and Hollas and Stansell (1988) using short-run profit functions also exclude the cost of capital.

Fifth, regulation plays a prominent role in shaping the business strategy of electric utilities, their behavior and, hence, their costs. IOUs are generally subject to COSR; POUs are not. The studies by Pescatrice and Trapani (1980) and Atkinson and Halvorsen (1986) are the only two that attempt to isolate the effects of regulation on costs. Atkinson and Halvorsen (1986) conclude that IOUs and POUs are both inefficient, but are no more or less inefficient than each other. Pescatrice and Trapani (1980) conclude that IOUs are less efficient than POUs because they are subject to COSR.

Sixth, with two exceptions, the studies do not account for differences in technology employed by the ownership types. Pescatrice and Trapani (1980) use a technology index, the weighted-average age of steam-electric generating plants used by each firm. Atkinson and Halvorsen (1986) use a dummy variable for ownership type that supposedly accounts for differences in technology. Other studies do not specifically account for different technologies that electric utilities may use or the way in which they operate.

Seventh, the studies generally ignore the effects of vertical integration on a utility's cost structure. As shown in Chapter 2, these effects may be substantial. The studies that compare generating costs of utilities that also transmit and distribute electricity fail to account for the vertical economies between generation, transmission, and distribution. This failure could bias results. Neuberg's study comparing the distribution cost structures of IOUs and POUs did not account for the amount of electric power either purchased by the distribution companies or transferred internally in a vertical structure. Clearly, the value of power coming into a distribution system is an important factor in the distribution cost structure, especially when comparing electric utilities that are exclusively distributors with those that distribute electricity in the final stage of a vertical process.

Eighth, the way in which a utility's generation and transmission assets are used in a control area may also influence its costs. Some utilities are themselves control areas. The generation and transmission assets of others are controlled by unrelated utilities. Still others are parts of the control areas of holding companies and power pools. Failure to account for these system characteristics could bias statistical results.

Because of these specification problems, we cannot conclude with certainty that IOUs, 
POUs, or RECs are inherently more resource efficient than one another. Therefore, those advocating municipalization of local distribution facilities or privatization of federal utilities are making their recommendations on bases other than economic efficiency considerations.

We can, however, conjecture on resource allocation and the efficient functioning of electric markets due to differences in input costs among ownership forms. We now turn to this issue.

\subsection{Ownership and Efficiency of Electric Markets}

Everything else equal, the production costs for POUs and RECs are lower than IOUs because of federal, state, and local subsidies. The types of subsidies are well known (Hill, 1988; Putnam, Hayes, and Bartlett, 1994). POUs are generally exempt from federal and state income taxes. Many RECs are exempt from local income taxes. The cost of capital for POUs and RECs is lower than IOUs because their borrowing costs are lower (e.g., municipals issue tax-exempt bonds). And, POUs and RECs have access to lower-cost "preference power" produced at federal generating facilities.

Putnam, Hayes, and Bartlett (1994) estimate that the total subsidy to POUs ( $\$ 5.0$ billion) and RECs ( $\$ 3.7$ billion) was $\$ 8.7$ billion in 1992 . If the subsidies were eliminated, the average selling price of electricity for POUs would increase $1.43 \notin / \mathrm{kWh}$ (17 percent greater than their average price in 1992); the average selling price of electricity for RECs would increase 1.85 $\phi / \mathrm{kWh}$ (16 percent greater than their average price in 1992). These amounts are substantial, especially when comparing them with expected decreases in electric market prices in many parts of the country as a result of restructuring. ${ }^{5}$

Clearly, these cost advantages could be affecting the efficiency of trade between control areas in the electric industry. Of the 138 U.S. control areas, four are operated by pools, 46 by POUs, 15 by RECs, and 73 by IOUs. Figure 7 expands Figure 4 by showing the control areas operated by RECs and POUs as shaded circles.

The cost advantages of POUs and RECs may inhibit trade among control areas that otherwise would engage in trade. They may also promote trade among control areas that otherwise would not trade because of cost considerations. Cost advantages and disadvantages

${ }^{5}$ The conclusions of a study by MSB Energy Associates (1996) do not agree with those of Putnam, Hayes, and Bartlett. 
Figure 7

Control Areas by Ownership in the U.S. Electric Industry

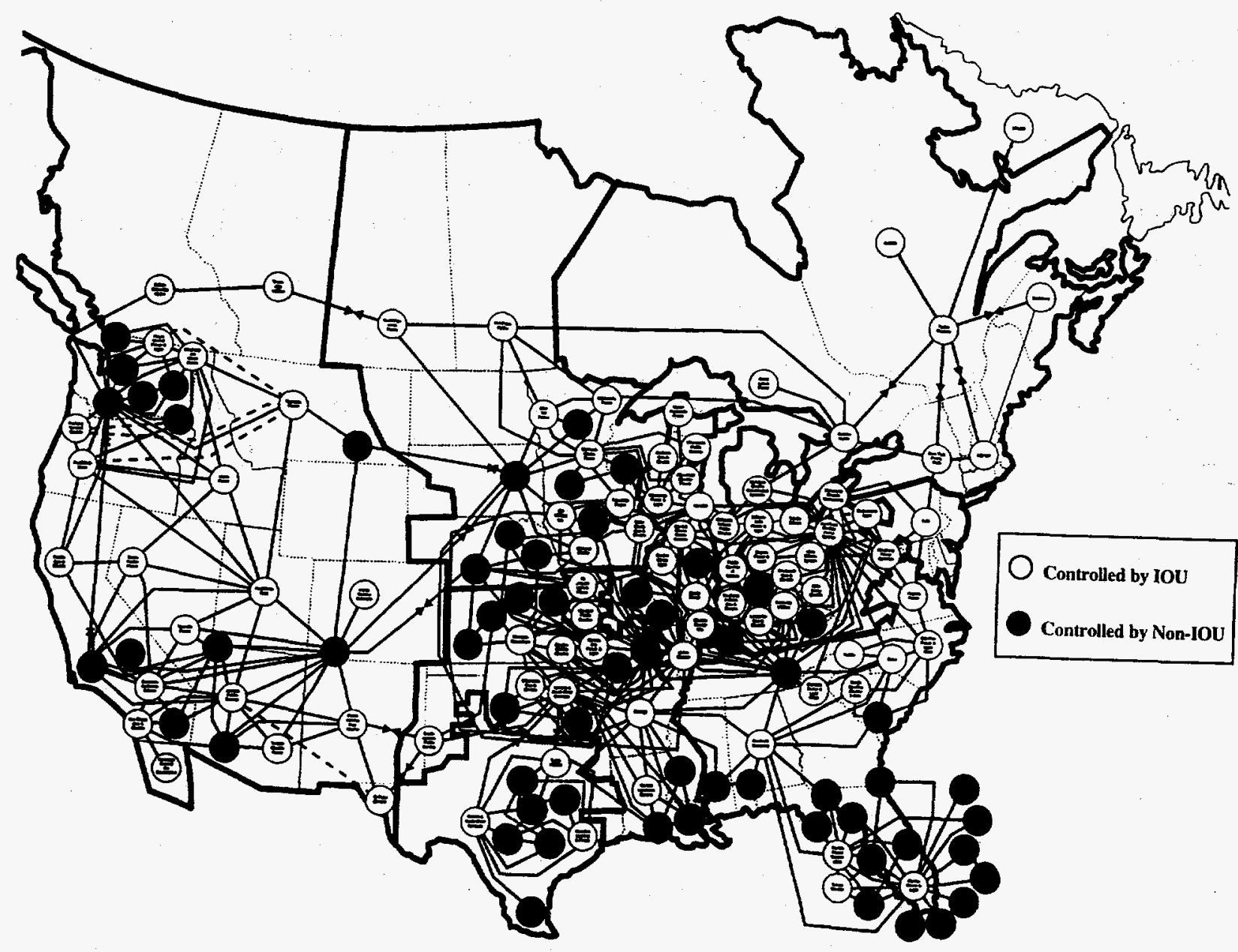

Source: Adapted from North American Electric Reliability Council (1995).

do not promote efficiency in existing electric markets. ${ }^{6}$

${ }^{6}$ The existence of many small control areas run by POUs and RECs may be another source of inefficiency because small control areas may not be able to exploit the scale economies of larger ones-if those economies exist. In the present discussion, we only consider inefficiencies attributable to input-cost advantages. 
Just as important, the cost advantages of POUs and RECs may not promote efficiency in restructured electric markets. The foundation of our prototype restructured electric market (Figure 5 in Chapter 3)--and the foundation of most of the restructuring proposals put forth in individual states to date--is a competitive spot market for electricity. This spot market serves as the basis for contracting arrangements of participants in the restructured electric market. Competitive bidding by electric generators in the spot market, controlled by an independent system operator, is the mechanism for operating these spot markets. Assuming the market is competitive, over time the bids must reflect costs. How can a market of this type result in the least-cost solution--i.e., be resource efficient--if some of the participants have input-cost advantages? Will the bids of the most efficient generators be selected? Or, will the bids of those generators with lower costs because of input-cost advantages--and not necessarily more inherently efficient--have an advantage? Similar arguments can be made for bilateral contracts between generators and wholesale and retail purchasers of electricity.

In many parts of the country, these input-cost advantages will not be a problem in creating efficient electric markets if the current pattern of ownership remains the same in the future. However, in other parts of the country where POUs and RECs are more prevalent (such as in the Northwest and Southeast), ownership could be a significant problem in creating efficient, competitive electric markets. 


\section{Conclusions}

Assuming that price and entry deregulation of the generating stage of electric markets will result in real cost savings in producing electricity, policymakers must determine if there are potential inefficiencies in other parts of the restructured market that may negate a portion of these cost savings or, in the extreme, even exceed them. Unfortunately, theory leads statistical evidence on these potential inefficiencies. The statistical evidence on the cost structure of electric utilities is fragmented, inconclusive, or outdated, making it difficult to (1) compare the efficiency of existing market structures and alternative ones and (2) prescribe design features of more efficient restructured markets.

Policymakers in states with high electric prices--and where prices are the predominant factor in electric-industry policymaking--face a dilemma. On one hand, if they let the structure of the industry evolve, they run the risk of losing important sources of jobs and income as industries migrate to states with lower electric prices. In extreme cases, they run the risk of not being re-elected or re-appointed. On the other hand, if policymakers choose to restructure their electric markets more radically allowing retail competition, they run the risk of making errors in crafting efficient electric markets because of insufficient information about the sources of (in)efficiencies in those markets. If the errors are easily reversible, the risk of restructuring under uncertainty is not as great as situations in which decisions are not as easily reversible because of, for example, vested interests in the new structure.

Interstate externalities compound problems with making errors in restructuring. Electric markets are not limited to state borders and the costs of regulating them are not limited to state capitals. Errors in one state have implications for others.

Policymakers in states with relatively low electric prices have the luxury of time to debate the futures of their electric industries. In considering a restructured market along the lines discussed in this report, these policymakers should look at four factors in detail: (1) the reliability of a restructured electric market; (2) income-distribution consequences for ratepayers and electric utilities; (3) social consequences such as effects on energy conservation, renewable energy, and the environment); and (4) economic efficiency considerations.

When considering economic efficiency, policymakers should systematically compare the net efficiency gains of moving from one market structure to another. This requires understanding the sources of efficiency and inefficiency in the existing market structure and the one being considered for adoption.

In evaluating the economic efficiency of different electric-market options, it is just as important to have answers for "if" questions as it is for "how" questions. For example, it is just as important to know if substantial vertical economies will be lost when restructuring an electric 
market as it is to know how to design the new market.

Unfortunately, limitations in our knowledge of the sources of (in)efficiencies in electric markets make it very difficult to answer these questions. Five issues, transcending federal, state, and local regulatory jurisdictions, warrant further investigation if policymakers want to make the best possible decision on economic efficiency grounds: (1) relative efficiency of forms of ownership; (2) scale economies in bulk power systems; (3) the extent of vertical integration in existing electric markets; (4) scale economies in distribution systems; and (5) institutional features of new electric markets. We discuss each in turn.

1. Relative Efficiency of Ownership Forms. Electric-industry observers can call for the privatization of federally owned (and other publicly owned) utilities on a philosophical basis. The "yardstick" function of publicly owned utilities may have made sense a half century ago, but does not make sense in competitive electric markets. Electric-industry observers can call for the privatization of publicly owned utilities on a fiscal basis. Operating subsidies for public power are substantial. Also, the sale of electric-utility assets would bring needed revenues to government treasuries. Electric-industry observers can call for the municipalization of local distribution utilities on an equity basis. Low-volume, captive customers in restructured electric markets may not have as much wherewithal to procure low-cost electricity as higher-volume customers.

However, electric-industry observers cannot call for sales of publicly owned utilities or municipalization of local distribution facilities on a resource-efficiency basis. Property-rights theory suggests that publicly owned utilities will be less efficient than privately owned ones. Statistical studies of relative efficiency, however, do not conclusively confirm or reject this hypothesis. First, most of the studies are misspecified in the sense that they do not account for the synergies between vertical stages of the industry. Second, most of the studies do not account adequately for factors that distinguish one ownership type from another, such as operating and ratemaking differences. Third, federal utilities have not been analyzed at all.

It is fairly straightforward to close this knowledge gap. Much is known about the technologies adopted by various ownership types; their differences in ratemaking; their differences in operation; their differences in input costs; and how vertical stages relate to one another in an electric system.

2. Scale Economies of Bulk Power Systems. A power delivery system consists of a bulk power system and one or more distribution systems. A bulk power system consists of (1) generating plants, (2) transmission lines linking the plants into a network, and (3) a control center. The control center's primary responsibilities are to dispatch power plants, commit plants for operation and maintenance, and trade with adjacent control areas.

Existing statistical studies of bulk power systems fragment these systems into generation and transmission components, and further fragment the generation stage by technology and fuel 
type. Early studies of scale in generation were conducted at the plant level; more recent studies have been conducted at the utility level. Fragmenting bulk power systems in this way for statistical analysis masks the underlying synergies between different types of power plants and the transmission lines that connect them in a grid with load centers.

For example, knowing that new combined-cycle gas turbine generating plants exploit scale economies at low levels of output and are competitive with other steam technologies does not indicate how these technologies should be combined in a system. Further, knowing that a utility's steam technologies have some minimum efficient scale is not very helpful in planning a power system. Plant economies and utility-technology economies are much different than system economies. For reliability reasons, bulk power systems are organized as "control areas" by the North American Electric Reliability Council. Therefore, the proper level of analysis for scale economies is the control area. The utility is the proper level of analysis only if it comprises an individual control area--and most of them do not.

The minimum efficient scale of control areas is an important issue in current restructuring debates around the country. In the California restructuring legislation, for example, the control areas of Pacific Gas and Electric, San Diego Gas and Electric, and Southern California Edison will be consolidated and run by an independent system operator (ISO). ${ }^{1}$ Other parts of the country are also exploring consolidation of control areas. For example, seven electric utilities in the Northwest (Idaho Power, Montana Power, PacifiCorp, Portland General Electric, Puget Sound Power and Light, Sierra Pacific, and Washington Water Power) intend to form IndeGo, an ISO, to operate as a single control area by mid 1997. The Electric Reliability Council of Texas, which includes nine privately and publicly owned control areas in Texas, will also become an ISO by mid 1997.

Are these pending consolidations efficient? What is the minimum efficient scale of bulk power systems? Are there diseconomies of scale after some threshold output level? Unfortunately, there is no statistical evidence to guide policymakers. Knowledge of scale economies and diseconomies is important because of the size discrepancy among control areas: the ten largest account account for 41.5 percent of peak demand, while the ten smallest account for 0.2 percent.

3. Vertical Integration. The most significant loss in restructured electric markets may be the vertical integration efficiencies in existing markets. Because of substitution possibilities between the generation and transmission stages and transmission and distribution stages, a vertically integrated utility may be better able to optimize the system and minimize costs than functionally separate generation, transmission, and distribution companies. Because of information needs on the other two stages when planning for any one, the vertically integrated

${ }^{1}$ The three publicly owned control areas in California must also agree to be part of the consolidated control area if they want to recoup transition costs from ratepayers. 
utility may be better able to plan the system. Transaction costs will increase in restructured markets.

To examine whether de-integrating existing vertically integrated markets is cost-effective, policymakers must compare the benefits of a restructured market--i.e., competition--with associated losses in vertical economies. Although somewat outdated, the existing studies show that the foregone economies of coordination between the generation and transmission stages could be substantial. However, statistical work is needed with more recent data.

Moreover, existing proposals to create an ISO to run the transmission grid sever the vertical ties between the transmission and distribution stages of the market. Distribution companies will be de-integrated from transmission-line owners (TLOs) and must compete with intermediaries such as brokers and marketers for retail customers. The vertical economies between transmission and distribution could be lost.

Unfortunately, existing statistical studies on the existence of vertical economies do not address the potential efficiencies between the transmission and distribution stages in the industry. Existing studies universally combine the transmission and distribution stages into one, estimating the vertical economies between generation and "distribution." This statistical simplification could potentially mask an important source of efficiency losses in restructured electric markets.

4. Scale Economies of Distribution Systems. Knowledge of the cost structure of distribution utilities is important when considering restructuring alternatives. First, large distribution systems could be broken into smaller ones if scale economies are exhausted at sufficiently low levels of throughput and should be broken into smaller ones if diseconomies of scale exist at higher levels of throughput. Second, if the minimum efficient scale is met by an existing distribution utility, new retail customers do not necessarily have to be served by existing distributors.

There is some evidence that economies of size and customer density are not important in distribution systems. That is, the average distribution company does not experience lower costs when serving more customers or serving a larger geographical area. The economies come from providing existing customers more electricity.

More statistical work needs to be done in this area. First, the existing studies are dated. Second, some studies of distribution scale economies are misspecified because they oversimplify the relationship between distribution companies and the upstream vertical stages of the industry.

5. Design Features of Restructured Markets. The discussion in Chapter 3 dealing with (in)efficiencies in restructured electric markets uncovered some potential problems with the relationship between the ISO and TLOs. More thought and creativity is needed in defining the relationships among ratemaking, property rights, levels of decisionmaking, incentives, and efficiency if the objective is to have an ISO minimize total system costs. 
There are various combinations of these institutional factors with one another, providing different incentives for market participants, and, therefore, economic efficiency. Specific recommendations must be tailored to local circumstances. However, four generalizations can be made.

First, vertical divestiture is a preferred alternative to functional unbundling in restructured markets if one of the objectives of policymakers is to ensure that regulated stages of a functionally unbundled utility do not subsidize unregulated ones. Second, property rights is an important consideration in defining the relationship between an ISO and TLOs. An ISO does not necessarily have the same incentives as TLOs. Third, the type of ratemaking imposed on the ISO and TLOs is important in providing incentives to behave efficiently. Performance-based regulation may not be the best choice in all situations. Fourth, responsibility for decisionmaking on grid expansion is important. The ISO and TLOs may not have the proper incentives to make efficient investments to expand the grid. 



\section{References}

Atkinson, Scott E. and Robert Halvorsen, 1980, "A Test of Relative and Absolute Price Efficiency in Regulated Utilities," The Review of Economics and Statistics, 62(1):81-88.

Atkinson, Scott E. and Robert Halvorsen, 1986, "The Relative Efficiency of Public and Private Firms in a Regulated Environment: The Case of U.S. Electric Utilities," Journal of Public Economics, 29(3):281-94.

Averch, Harvey and Leland L. Johnson, 1962, "Behavior of the Firm under Regulatory Constraint," American Economic Review, 52(X):1052-1069.

Bailey, Elizabeth, 1973, Economic Theory of Regulatory Constraint, Lexington, MA: Lexington Books.

Baldick, Ross and Edward Kahn, 1993, "Network Costs and the Regulation of Wholesale Competition in Electric Power," Journal of Regulatory Economics, 5(4):367-384.

Baumol, William J., John C. Panzar, and Robert D. Willig, 1982, Contestable Markets and the Theory of Industry Structure, San Diego: Harcourt Brace Jovanovich.

Berry, Dan Michael, 1994; "Private Ownership Form and Productive Efficiency: Electric Cooperatives versus Investor-Owned Utilities," Journal of Regulatory Economics, 6(4): 399-420.

Christensen, Laurits R., and William H. Greene, 1976, "Economies of Scale in U.S. Electric Power Generation," Journal of Political Economy, August, pp. 655-676.

Claggett, E. Tylor, Daniel R. Hollas, and Stanley R. Stansell, 1995, "The Effects of Ownership Form on Profit Maximization and Cost Minimization Behavior within Municipal and Cooperative Electrical Distribution Utilities," The Quarterly Review of Economics and Finance, 35(Special):533-550.

Comnes, G. Alan, Steven Stoft, Nathaniel Greene, and Lawrence J. Hill, 1995, PerformanceBased Ratemaking for Electric Utilities: Review of Plans and Analysis of Economic and Resource-Planning Issues, Berkeley, California: Lawrence Berkeley Laboratory, LBL-37577, UC-1320, November.

Cote, Daniel O., 1989, "Firm Efficiency and Ownership Structure: The Case of U.S. Electric Utilities Using Panel Data," Annals of Public and Cooperative Economics, 60(4), OctoberDecember, pp. 431-50. 
Cowing, Thomas G. and V. Kerry Smith, 1978, "The Estimation of a Production Technology: A Survey of Econometric Analyses of Steam-Electric Generation," Land Economics, 54(2):156186.

Crew, Michael A. and Paul R. Kleindorfer, 1986, The Economics of Public Utility Regulation, Cambridge: The MIT Press.

De Alessi, Louis, 1975, "Some Effects of Ownership on the Wholesale Prices of Electric Power," Economic Inquiry, 13(X):526-38.

DiLorenzo, Thomas J. and Ralph Robinson, 1982, "Managerial Objectives Subject to Political Market Constraints: Electric Utilities in the U.S.," Quarterly Review of Economics and Business, 22(2):113-25.

Edison Electric Institute, 1995, Statistical Yearbook of the Electric Utility Industry, 1994, Washington, DC.

Energy Information Administration, 1995, Financial Statistics of Major U.S. Investor-Owned. Electric Utilities, 1994, Washington, DC, DOE/EIA-0437(94)/1, December.

Fare, R., S. Grosskopf, and J. Logan, 1985, "The Relative Performance of Publicly- Owned and Privately-Owned Electric Utilities," Journal of Public Economics, 26(XX):89-106.

Federal Energy Regulatory Commission, 1995, Promoting Wholesale Competition through Open Access, Non-Discriminatory Transmission Services by Public Utilities; Recovery of Stranded Costs by Public Utilities and Transmitting Utilities, Docket Nos. RM95-8-000 and RM94-7-001, Notice of Proposed Rulemaking and Supplemental Notice of Proposed Rulemaking, Washington, DC, March 29.

Federal Energy Regulatory Commission, 1996, Promoting Wholesale Competition through Open Access, Non-Discriminatory Transmission Services by Public Utilities; Recovery of Stranded Costs by Public Utilities and Transmitting Utilities, Docket Nos. RM95-8-000 and RM94-7-001, Final Rule, Order No. 888, Washington, DC, April 24.

Gilsdorf, Keith, 1994, "Vertical Integration Efficiencies and Electric Utilities: A Cost Complementarity Perspective," Quarterly Review of Economics and Finance, 34(3):261-282.

Hausman, William J. and John L. Neufeld, 1991, "Property Rights versus Public Spirit: Ownership and Efficiency of U.S. Electric Utilities Prior to Rate-of-Return Regulation," Review of Economics and Statistics, 73(3):414-423. 
Henderson, J. Stephen, 1985, "Cost Estimation for Vertically Integrated Firms: The Case of Electricity," In Michael Crew, Editor, Analyzing the Impact of Regulatory Change in Public Utilities, Lexington: Lexington Books, pp. 75-94.

Hill, Lawrence J., 1988, Public Power in the U. S. Electric Utility Industry: Regulatory Issues and Comparative Financial Indicators across Ownership Types, Oak Ridge National Laboratory, Oak Ridge, Tennessee, ORNL/TM-10497, January.

Hill, Lawrence J., 1995, A Primer on Incentive Regulation for Electric Utilities, Oak Ridge National Laboratory, Oak Ridge, Tennessee, ORNL/CON-422, October.

Hirst, Eric and Brendan Kirby, 1996, Electric-Power Ancillary Services, Oak Ridge, Tennessee: Oak Ridge National Laboratory, ORNL/CON-426, February.

Hogan, William W., 1992, "Contract Networks for Electric Power Transmission," Journal of Regulatory Economics, 4(3):211-242.

Hollas, Daniel R. and Thomas S. Friedland, 1980, Competition, Regulation, and Second-Degree Price Discrimination in the Municipal Electric Industry," Quarterly Review of Economics and Business, 20(3):41-59.

Hollas, Daniel R. and Stanley R. Stansell, 1988, "An Examination of the Effect of Ownership Form on Price Efficiency: Proprietary, Cooperative, and Municipal Electric Utilities," Southern Economic Journal, 55(XX):336-50.

Hollas, Daniel R. and Stanley R. Stansell, 1991, "Regulation, Ownership Form, and the Economic Efficiency of Rural Electric Distribution Cooperatives," The Review of Regional Studies, 21(2):201-20.

Huettner, David A. and John H. Landon, 1978, "Electric Utilities: Scale Economies and Diseconomies," Southern Economic Journal, 44(4):883-912.

Joskow, Paul L. and Richard Schmalensee, 1983, Markets for Power: An Analysis of Electrical Utility Deregulation, Cambridge, Massachusetts: The MIT Press.

Kahn, Edward, 1996, "The Electricity Industry in Spain," The Electricity Journal, 9(2):46-55.

Kahn, Edward and Steven Stoft, 1995, Organization of Bulk Power Markets: A Concept Paper, Berkeley, California: Lawrence Berkeley Laboratory, LBL-37508, December.

Kamerschen, David R. and Herbert G. Thompson, 1993, "Nuclear and Fossil Fuel Steam Generation of Electricity: Differences and Similarities," Southern Economic Journal, 60(1): 1427. 
Kaserman, David L. and John W. Mayo, 1991, "The Measurement of Vertical Economies and the Efficient Structure of the Electric Utility Industry," Journal of Industrial Economics, 39(5):483502.

Kirby, Brendan and Eric Hirst, 1996, Ancillary-Service Costs for 12 U.S. Electric Utilities, Oak Ridge, Tennessee: Oak Ridge National Laboratory, ORNL/CON-427, March.

Koh, Dong-Soo, Sanford V. Berg, and Lawrence W. Kenny, 1996, "A Comparison of Costs in Privately Owned and Publicly Owned Electric Utilities: The Role of Scale," Land Economics, 72(1):56-65.

Kwoka, John E., 1996, "Vertical Integration and its Alternatives for Achieving Cost Efficiency in Electric Power," Unpublished Paper.

Landon, John H., 1983, "Theories of Vertical Integration and Their Application to the Electric Industry," Antitrust Bulletin, X(X):101-30.

Liebenstein, Harvey, 1966, "Allocative Efficiency vs. 'X-Efficiency,"' American Economic Review, 56(X):392-415.

Meyer, Robert A., 1975, "Publicly Owned Versus Privately Owned Utilities: A Policy Choice," Review of Economics and Statistics, 57(4):391-99.

Moore, Thomas Gale, 1970, "The Effectiveness of Regulation of Electric Utility Prices," Southern Economic Journal, 36(X):365-75.

MSB Energy Associates, 1996, "Explaining Public Power's Low Rates: A Critical Review of the EEI-Sponsored Report, 'Subsidies and Unfair Competitive Advantages Available to Publicly Owned and Cooperative Utilities,"' Middleton, Wisconsin, April 5.

Neuberg, Leland Gerson, 1977, "Two Issues in the Municipal Ownership of Electric Power Distribution Systems," The Bell Journal of Economics, 8(1):303-23.

North American Electric Reliability Council, 1995, NERC Operating Manual, Princeton, New Jersey.

Pacific Gas and Electric Company, San Diego Gas and Electric Company, and Southern California Edison Company, 1996, Joint Application of Pacific Gas and Electric Company, San Diego Gas and Electric Company, and Southern California Edison Company for Authorization to Convey Operational Control of Designated Jurisdictional Facilities to an Independent System Operator, April 29. 
Pescatrice, Donn R. and John M. Trapani, 1980, "The Performance and Objectives of Public and Private Utilities Operating in the United States," Journal of Public Economics, 13(X):259-76.

Putnam, Hayes, and Bartlett, Inc., 1994, Subsidies and Unfair Competitive Advantages Available to Publicly-Owned and Cooperative Utilities, Washington, D.C., September.

Roberts, Mark J., 1986, "Economies of Density and Size in the Production and Delivery of Electric Power," Land Economics, 62(4):378-87.

Schap, David, 1986, Municipal Ownership in the Electric Utility Industry: A Centennial View, New York: Praeger Publishers.

Thompson, Herbert G., David Alan Hovde, and Louis Irwin, 1996, Economies of Scale and Vertical Integration in the Investor-Owned Electric Utility Industry, NRRI 96-05, Columbus, Ohio: The National Regulatory Research Institute, January.

Weiss, Leonard W., 1975, "Antitrust in the Electric Power Industry," In Almarin Phillips, Editor, Promoting Competition in Regulated Markets, Washington, D.C.: The Brookings Institution.

Yunker, James A., 1975, "Economic Performance of Public and Private Enterprise: The Case of U.S. Electric Utilities," Journal of Economics and Business, 28(1):60-67.

Zieschang, Kimberly D., 1983, "A Note on the Decomposition of Cost Efficiency into Technical and Allocative Components," Journal of Econometrics, 23(3):401-405. 
ORNL/CON-436

\section{INTERNAL DISTRIBUTION}

1. D. C. Bauer

2. L. W. Baxter

3. V. D. Baxter

4. L. G. Berry

5. D. J. Bjornstad

6. M. A. Brown

7. J. E. Christian

8. G. E. Courville

9. T. R. Curlee

10. P. D. Fairchild

11. S. W. Hadley

12. L. J. Hill

13. E. Hirst

14. P. J. Hughes

15. B. J. Kirby

16. R. M. Lee
17. P. N. Leiby

18. J. M. MacDonald

19. V. C. Mei

20. D. E. Reichle

21. A. C. Schaffhauser

22. M. Schweitzer

23. R. B. Shelton

24. J. J. Tomlinson

25. B. E. Tonn

26. J. W. Van Dyke

27. J. VanCoevering

28. T. J. Wilbanks

29. Central Research Office

30. Document Reference Section

31. Laboratory Records (RC)

\section{EXTERNAL DISTRIBUTION}

32. Dr. Lilia A. Abron, President, PEER Consultants, P.C., 1000 N. Ashley Drive, Suite 312, Tampa, FL 33602

33. Dr. Thomas E. Drabek, Professor, Department of Sociology, University of Denver, Denver, CO 80208-0209

34. Dr. Stephen G. Hildebrand, Director, Environmental Sciences Division, Oak Ridge National Laboratory, P.O. Box 2008, Oak Ridge, TN 37831-6037

35. Dr. Susan F. Tierney, The Economic Resource Group, Inc., One Mifflin Place, Cambridge, MA 02138

36. Dr. C. Michael Walton, Ernest H. Cockrell Centennial Chair in Engineering and Chairman, Department of Civil Engineering, University of Texas at Austin, Austin, TX 78712-1076

37-38. OSTI, U.S. Department of Energy, P.O. Box 62, Oak Ridge, TN 37831

39. Office of Assistant Manager for Energy Research and Development, DOE/ORO, P.O. Box 2001, Oak Ridge, TN 37831-8600

40-550. External Electric Industry Policy Studies group distribution mailing list and extra copies to E. D. McFadden, $4500 \mathrm{~N}$, G-23 